\title{
Lack of Heme 0xygenase-1 Induces Inflammatory Reaction and Proliferation of Muscle Satellite Cells after Cardiotoxin-Induced Skeletal Muscle Injury
}

\author{
Magdalena Kozakowska, ${ }^{*}$ Katarzyna Pietraszek-Gremplewicz, ${ }^{*}$ Maciej Ciesla, ${ }^{*}$ Marta Seczynska, ${ }^{*}$ Iwona Bronisz-Budzynska, \\ Paulina Podkalicka, ${ }^{*}$ Karolina Bukowska-Strakova, ${ }^{* \dagger}$ Agnieszka Loboda, ${ }^{*}$ Alicja Jozkowicz, ${ }^{*}$ and Jozef Dulak
}

From the Department of Medical Biotechnology, * Faculty of Biochemistry, Biophysics and Biotechnology, the Jagiellonian University; Krakow; and the Department of Clinical Immunology, ${ }^{\dagger}$ Institute of Pediatrics, Faculty of Medicine, Jagiellonian University Medical College, Krakow, Poland

\author{
Accepted for publication \\ October 23, 2017. \\ Address correspondence to \\ Jozef Dulak, Ph.D., D.Sc., \\ Department of Medical \\ Biotechnology, Faculty of \\ Biochemistry, Biophysics and \\ Biotechnology, Jagiellonian \\ University, Gronostajowa 7, \\ 30-387 Krakow, Poland. \\ E-mail: jozef.dulak@uj.edu.pl.
}

\begin{abstract}
Heme oxygenase-1 (H0-1, Hmox1) regulates viability, proliferation, and differentiation of many cell types; hence, it may affect regeneration of injured skeletal muscle. Here, we injected cardiotoxin into gastrocnemius muscle of $\mathrm{Hmox}^{+/+}$and $\mathrm{Hmox}^{-/-}$animals and analyzed cellular response after muscle injury, focusing on muscle satellite cells (SCs), inflammatory reaction, fibrosis, and formation of new blood vessels. $\mathrm{H} 0-1$ is strongly induced after muscle injury, being expressed mostly in the infiltrating leukocytes ( $\mathrm{CD} 45^{+}$cells), including macrophages ( $\mathrm{F} 4 / 80^{+}$cells). Lack of $\mathrm{H0}-1$ augments skeletal muscle injury, evidenced by increased creatinine kinase and lactate dehydrogenase, as well as expression of monocyte chemoattractant protein-1, IL-6, IL-1 $\beta$, and insulin-like growth factor-1. This, together with disturbed proportion of M1/M2 macrophages, accompanied by enhanced formation of arterioles, may be responsible for shift of $\mathrm{Hmox}^{-/-}$myofiber size distribution toward larger one. Importantly, H0-1-deficient SCs are prone to activation and have higher proliferation on injury. This effect can be partially mimicked by stimulation of $\mathrm{Hmox}^{+/+} \mathrm{SCs}$ with monocyte chemoattractant protein-1, IL-6, IL-1 $\beta$, and is associated with increased MyoD expression, suggesting that $H$ mox ${ }^{-/-}$ SCs are shifted toward more differentiated myogenic population. However, multiple rounds of degeneration/regeneration in conditions of $\mathrm{HO}-1$ deficiency may lead to exhaustion of SC pool, and the number of SCs is decreased in old $\mathrm{Hmox}^{-1-}$ mice. In summary, $\mathrm{HO}-1$ modulates muscle repair mechanisms preventing its uncontrolled acceleration. (Am J Pathol 2018, 188: 491-506; https:// doi.org/10.1016/j.ajpath.2017.10.017)
\end{abstract}

Striated muscles consist of highly differentiated muscle fibers and are characterized by a slow cell turnover. Apart from mature myofibers, relatively low number of inflammatory cells (resident macrophages) and progenitor cells [muscle satellite cells (SCs)] are also present in intact muscles, together with fibroblasts, adipocytes, and their progenitors [fibroadipogenic progenitors (FAPs)], endothelial cells, and pericytes. ${ }^{1-6}$ When it comes to myotrauma (eg, induced by cardiotoxin, CTX) the situation changes dramatically. Within a few hours cell debris and activated resident macrophages induce massive infiltration with neutrophils, followed by macrophages, mostly of proinflammatory M1 phenotype. ${ }^{6-9}$ During the first few days, removal of cell debris by macrophages proceeds concomitantly with activation of key players in skeletal muscle regeneration, namely SCs. In response to growth factors [hepatocyte growth factor, insulin-like growth factor

Supported by National Science Center MAESTRO grant 2012/06/A/ NZ1/00004 (J.D.) and Polish Ministry of Science and Higher Education Iuventus Plus grant IP2012 025572 (M.K.). Faculty of Biochemistry, Biophysics and Biotechnology of Jagiellonian University is a partner of the Leading National Research Center (KNOW) supported by the Ministry of Science and Higher Education.

Disclosures: None declared.

Current address of K.P.-G., Department of Cell Pathology, Faculty of Biotechnology University of Wroclaw, Wroclaw, Poland; of M.C., Division of Molecular Hematology, Lund University, Lund, Sweden; of M.S., Cambridge Institute for Medical Research, University of Cambridge, Cambridge, United Kingdom. 
(IGF)-1, fibroblast growth factor-2] and proinflammatory cytokines [monocyte chemoattractant protein (MCP)-1/ chemokine (C-C motif) ligand 2, IL-1 $\beta$, IL-6] SCs enter the cell cycle and proliferate robustly, expanding their population and changing their phenotype. ${ }^{2,5,10} \mathrm{SC}$ marker, paired box protein 7 ( $\operatorname{Pax} 7)$ transcription factor, is necessary for cell cycle progression, acting upstream of the group of muscle regulatory factors (Myf5, MyoD, myogenin, and Myf6) and controlling their sequential expression and activity. ${ }^{11,12}$ During successive rounds of proliferation SCs are converted into myoblasts that then differentiate further to fuse into multinucleated myotubes, starting expression of proteins of mature skeletal muscles. ${ }^{2,4,5,10,13}$ This process is accompanied by the change in the macrophage phenotype within injured muscle. Transition from M1 to M2 starts about the third day after injury and modifies the impact of macrophages on SCs-from sustaining activation and proliferation to promotion of differentiation..$^{9,14,15}$ Finally, to fully regenerate skeletal muscle, reconstruction of intramuscular capillaries and arterioles in the processes of angiogenesis and arteriogenesis has to take place, as well as formation of a fibrotic scar. Achieving that can in turn provide a proper niche and supply of nutrients for maturing muscle cells. ${ }^{4,6}$

The biological effects of heme oxygenase-1 (HO-1, encoded by Hmoxl) extend far beyond its classic enzymatic function-degradation of heme to carbon monoxide, biliverdin, and iron. ${ }^{16}$ Lack of HO-1 strongly induces chronic inflammatory reaction with increased monocyte/macrophage in spleen and elevated proinflammatory cytokines. Reverse effect on the expression of tumor necrosis factor $-\alpha$, IL-1 $\beta$, and IL- 6 can be exerted in macrophages by HO-1/carbon monoxide stimulation. ${ }^{16-18} \mathrm{HO}-1$ as immunomodulatory factor promotes macrophage switch from M1 to M2 phenotype. ${ }^{19}$ Furthermore, HO-1 is cytoprotective and antiapoptotic in different cell types. ${ }^{16,20}$ It may also promote angiogenesis, and by induction of proangiogenic vascular endothelial growth factor (VEGF) and stromal cell-derived factor- $1 \alpha$ it leads to increased formation of capillaries during wound healing and in ischemic hind limbs. ${ }^{16,21}$ Moreover, HO-1 may reduce fibrosis in kidney, liver, and lungs. ${ }^{22,23}$ Finally, in many cell types HO-1 affects differentiation. ${ }^{24}$ Recently, it was demonstrated that $\mathrm{HO}-1$ influences in vitro differentiation of myoblasts (C2C12 cell line and primary myoblasts). ${ }^{25}$ Low HO-1 expression increases the differentiation rate but makes myoblasts prone to apoptosis, whereas the opposite effect can be observed in cells overexpressing HO- $1 .{ }^{25}$ Importantly, HO-1 appears to be a potent modulator of the miRNA expression, with especially strong effect exerted on muscle-specific myomirs. ${ }^{25,26}$ However, hypoxia-induced genetic overexpression of HO-1 in muscles during the first days of ischemia enhances cell viability and facilitates recovery on injury. ${ }^{27}$

Although HO-1 may be considered as a potential target for improving skeletal muscle regeneration, no studies on its role in this process have been performed so far. We aimed to investigate whether the lack of HO-1 will influence inflammatory reaction, proliferation of SCs, and maturation of new myofibers, as well as if it affects angiogenesis, arteriogenesis, and fibrosis in regenerating skeletal muscle.

\section{Materials and Methods}

\section{Animal Models}

All animal procedures and experiments were performed after approval by the First Local Ethical Committee on Animal Testing at Jagiellonian University (66/2013). Animals were kept in specific pathogen-free conditions with water and food available ad libitum. C57BL/6xFVB $H_{m o x I^{+/+}}$and Hmoxl ${ }^{-/-}$breeding pairs were originally kindly provided by Dr. Anupam Agarwal, University of Alabama, Birmingham, AL, in 2004. Female age-matched mice (approximately 12 weeks old) were used for the myoinjury experiment. In addition, for analysis of SC population in intact skeletal muscle 6-, 12-, 15-, 18-, and 24-month-old animals were used.

Gastrocnemius muscles of Hmoxl $I^{+/+}$and Hmoxl ${ }^{-/-}$ mice were injected with $25 \mu \mathrm{L}$ of $20 \mu \mathrm{mol} / \mathrm{L}$ CTX (SigmaAldrich, St. Louis, MO) in saline. Muscles of control mice were injected intramuscularly with saline and sacrificed immediately. Animals were provided with analgesia $(50 \mu \mathrm{L}$, $0.03 \mathrm{mg} / \mathrm{mL}$ buprenorphine) after injection and on the next 2 days. To induce multiple injury CTX injections were repeated three times every 2 weeks, and analgesia was applied after each injection. Animals were sacrificed on the 1st, 3rd, 7th, 14th, and 28th day after CTX-induced injury (5 Hmoxl $\mathrm{I}^{+/+}$and $5 \mathrm{Hmoxl}^{-/-}$per time point) and 1st, 3rd, and 28th day after triple injury. One day before sacrifice 150 $\mu \mathrm{L}$ of 5-ethynyl-2'-deoxyuridine (Edu; Thermo Fisher, Waltham, MA) in saline $(2 \mathrm{mg} / \mathrm{mL})$ was injected intraperitoneally into CTX-injured or control mice.

After euthanasia injured and control muscles were collected and snap-frozen in liquid nitrogen (for RNA and protein isolation) or preserved in formalin (for histologic analysis). Orbital sinus blood sampling from mice was performed directly to EDTA-coated tubes. Collected blood was analyzed by $\mathrm{ABC}$ Vet equipment (Horiba ABX, Kyoto, Japan).

\section{Plasma CPK and LDH Measurement}

Plasma was obtained from blood collected from the vena cava just before the terminal procedure, by centrifugation of the clot. Activities of creatine phosphokinase (CPK) and lactate dehydrogenase (LDH) were measured with diagnostic Liquick Cor-CK and Liquick Cor-LDH kit, respectively (Cormay, Warszawa, Poland) according to the vendor's instruction. 


\section{Histologic and Immunohistofluorescence Staining}

Gastrocnemius muscles, with tightly associated soleus muscles, were placed in $10 \%$ formalin for 48 hours. After paraffin embedding, sections were cut, deparaffinized, and subjected to histologic or immunohistofluorescence staining.

Hematoxylin and eosin staining (Sigma-Aldrich) was performed to assess intensity of inflammatory infiltration and muscle degeneration (arbitrary units: $0=$ no signs of inflammation; $1=$ any sign of leukocyte infiltration and myofiber swelling; $2=$ clearly visible inflammation, myofiber swelling, and rhabdomyolysis; $3=$ signs of inflammation, myofiber swelling, and rhabdomyolysis take up more than a half of field of view; $4=$ all muscle visible in the field of view is infiltrated and degenerated), level of regeneration (percentage of centrally nucleated myofibers in the field of view), and size of myofibers (measurement of the area of at least 50 fibers per mouse; ImageJ software version 1.50i; NIH, Bethesda, MD; http://imagej.nih.gov/ij). Trichrome staining was performed by sequential treatment of slides with Biebrich Scarlet-Acid Fuchsin, phosphotungstic acid/phosphomolybdic acid, and Aniline Blue (Sigma-Aldrich, according to the vendor's instructions) to visualize the collagen (arbitrary units: $0=$ no signs of collagen deposition; 1 = any sign of collagen deposition; $2=$ clearly visible collagen deposition; $3=$ collagen deposition takes up more than a half of field of view). All analyses were performed by an observer (M.K.) blinded to the treatment of animals, 10 images of damaged area per mouse were analyzed.

For immunohistofluorescence staining of paraffin sections retrieval of antigens was performed in citric buffer. Then slides were blocked with phosphate-buffered saline (PBS) with $5 \%$ bovine serum albumin (BioShop, Burlington, ON, Canada) and 5\% goat serum (Sigma-Aldrich), and primary antibodies were applied overnight in $4^{\circ} \mathrm{C} \mathrm{Pax} 7$ (dilution 1:100 and $\alpha$-smooth muscle actin dilution 1:200; both from Abcam, Cambridge, UK). Secondary anti-rabbit Alexa Fluor 568 or 488 (Thermo Fisher, Waltham, MA) were applied for 2 hours (dilution 1:200-1:500) together with Hoechst 33342 (1 $\mu \mathrm{g} / \mathrm{mL}$; Sigma-Aldrich). To visualize proliferating cells the slides were then proceeded with Click-iT Edu Alexa Fluor 488 Imaging Kit (Thermo Fisher), according to the vendor's manual. To analyze $\mathrm{Pax} 7^{+} \mathrm{Edu}^{+}$ cells at least 10 fields of view per damaged area of muscle were analyzed.

Staining of necrotic fibers was performed on muscle sections after citric buffer-mediated antigen retrieval, ${ }^{28}$ followed by blocking with $10 \%$ goat serum and 2 hours of incubation with goat anti-mouse IgG/IgM/IgA Alexa Fluor 488 (Thermo Fisher). Nuclei were counterstained with Hoechst 33342. To analyze necrosis in the damaged area, percentage of necrotic fibers among total fiber number was counted.

For immunohistofluorescence staining of HO-1 and CD45 or F4/80 colocalization gastrocnemius muscle was preserved in OCT freezing medium in isopentane, cooled in a bath of liquid nitrogen. Frozen muscle sections of control animals and mice injured with CTX were stained with HO-1 (SPA894; Enzo, Farmingdale, NY) and with CD45 (30-F11; eBioscience, San Diego, CA) or F4/80 (MCA497R; BioRad, Hercules, CA), as described previously. ${ }^{23}$ Sections were covered with fluorescence mounting medium (Dako, Carpinteria, CA), visualized under fluorescent confocal microscope (Carl Zeiss, Thornwood, NY) and analyzed in ImageJ (NIH).

Terminal deoxynucleotidyl transferase-mediated dUTP nick-end labeling (TUNEL) staining of DNA fragmentation (Millipore, Billerica, MA) was performed according to the vendor's instruction and followed by overnight incubation at $4^{\circ} \mathrm{C}$ with primary anti-HO-1 antibody (dilution 1:50; SPA894; Enzo) and 2-hour incubation with anti-rabbit Alexa Fluor 568 secondary antibody (dilution 1:200).

\section{Fluorescence-Activated Cell Sorting}

SCs were isolated as previously described. ${ }^{29}$ Gastrocnemius muscles were minced and digested with $5 \mathrm{mg} / \mathrm{mL}$ collagenase IV (Gibco-Thermo Fisher, Waltham, MA) and 1.2 U/ $\mathrm{mL}$ dispase (Gibco-Thermo Fisher) at $37^{\circ} \mathrm{C}$ for 45 minutes. Cell suspension was filtered and centrifuged.

For analysis of SCs $\left[\mathrm{CD} 45^{-} \mathrm{CD} 31^{-}\right.$stem cell antigen-1 (Sca1) $\left.)^{-} \alpha 7 \mathrm{i}^{+} \mathrm{CD} 34^{+} / \mathrm{CD} 34^{-}\right]$, a pellet of FAP $\left(\mathrm{CD} 45^{-} \mathrm{CD} 31^{-} \alpha 7 \mathrm{i}^{-} \mathrm{Sca} 1^{+} \mathrm{CD} 34^{+}\right)$, endothelial cells $\left(\mathrm{CD} 31^{+} \mathrm{CD} 45^{-}\right)$, and inflammatory cells $\left(\mathrm{CD} 45^{+} \mathrm{CD} 31^{-}\right)$ was resuspended in PBS $+2 \%$ fetal bovine serum. Thirtyminute incubation on ice was performed with the following antibodies: rat anti-mouse $\alpha 7$ i-phycoerythrin (PE) (dilution 1:15; R\&D Systems, Minneapolis, MN), rat anti-mouse CD34-Alexa Fluor 700 (dilution 1:30), rat anti-mouse CD45-allophycocyanin (APC)-eFluor 780 (dilution 1:30), rat anti-mouse CD31-APC (dilution 1:30), rat anti-mouse Sca1-PE-cyanine (Cy)7 (dilution 1:30) (all from BD Biosciences, Franklin Lakes, NJ).

For analysis of macrophages [total macrophages:

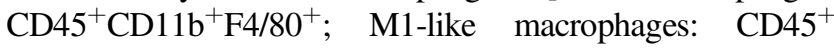
$\mathrm{CD}_{11 \mathrm{~b}}{ }^{+} \mathrm{F} 4 / 80^{+}$major histocompatibility complex II (MHCII $)^{\text {high }} \mathrm{CD} 206^{\text {low }}$; M2-like macrophages: $\mathrm{CD} 45^{+}$


with rat anti-mouse CD45-APC-eFluor 780 (dilution 1:30), rat anti-mouse F4/80-APC (dilution 1:30), rat anti-mouse MHCIIPE-Cy7 (dilution 1:30), rat anti-mouse 11b-PE (dilution 1:30) (all from BD Biosciences), and rat anti-mouse CD206-peridinin-chlorophyll protein/Cy5.5 (dilution 1:30; BioLegend, San Diego, CA).

For intracellular protein detection in SCs, staining of surface antigens was followed by fixation and permeabilization with BD IntraSure Kit (BD Biosciences) according to the vendor's protocol. Primary rabbit polyclonal anti-Pax7 (dilution 1:200; Abcam) antibodies were applied, and appropriate goat-anti mouse Alexa Fluor 568 secondary antibody (dilution 1:400) was used. Cell cycle phases were 
determined from Hoechst 33342 staining. The stained cells were analyzed with LSRFortessa flow cytometer (BD Biosciences).

\section{Isolation of SCs}

To isolate SCs (for analysis on RNA level or cell culture) the muscles were prepared similarly as for fluorescenceactivated cell sorting (FACS) analysis. Cells were incubated with rat anti-mouse $\alpha 7 \mathrm{i}-\mathrm{PE}$ (dilution 1:15; R\&D Systems), rat anti-mouse CD34-fluorescein isothiocyanate (dilution 1:30), rat anti-mouse CD45-APC (dilution 1:30), rat antimouse Sca1-PE-Cy7 (dilution 1:30), rat anti-mouse CD31-APC (dilution 1:30) (all from BD Biosciences). After 30-minute incubation cells were sorted with MoFlo XDP cell sorter (Beckman Coulter, Pasadena, CA).

\section{Primary SC Culture and Proliferation Analysis}

Five thousand SCs isolated by FACS were cultured on gelatin-coated plates (Sigma-Aldrich) in growth medium that consisted of Dulbecco's modified Eagle's medium 4.5 g/L glucose (Lonza, Basel, Switzerland), $20 \%$ fetal bovine serum (Biowest, Nuaille, France), $10 \%$ horse serum (PAA Laboratories, Chicago, IL), and $5 \mathrm{ng} / \mathrm{mL}$ basic fibroblast growth factor (PeproTech, Rocky Hill, NJ). On the next day, cells were stimulated for 24 hours with a mix of proinflammatory cytokines that included IL-6 $(1 \mathrm{ng} / \mathrm{mL})$, IL-1 $\beta$ $(0.1 \mathrm{ng} / \mathrm{mL})$, and MCP-1 (100 ng/mL) (all from SigmaAldrich). Afterward (2 days after sort), Edu $(10 \mu \mathrm{mol} / \mathrm{L})$ was added for 2 hours, and $\mathrm{Edu}^{+}$cells were visualized according to the vendor's instructions.

In addition, cells were immunostained for MyoD. To this purpose blocking was performed with $3 \%$ bovine serum albumin in PBS for 1 hour, and primary mouse anti-MyoD antibody (dilution 1:100; BD Biosciences) in blocking buffer was applied overnight at $4^{\circ} \mathrm{C}$. Afterward, cells were rinsed and incubated for 2 hours with goat-anti-mouse Alexa Fluor 488 secondary antibody (dilution 1:200 in PBS) and Hoechst $33342(2 \mu \mathrm{g} / \mathrm{mL})$. Percentage of $\mathrm{Edu}^{+}$and $\mathrm{MyoD}^{+}$cells was analyzed under fluorescent microscope Nikon (Melville, NY) Eclipse in at 20 fields of view per mouse.

\section{RNA Isolation and Quantitative RT-PCR}

Total RNA was isolated from muscle fragments by homogenization in $1 \mathrm{~mL}$ of Quiazol Total RNA Isolation Reagent using Tissue Lyzer (Qiagen, Hilden, Germany), according to the vendor's manual. Concentration and quality of RNA was determined spectrophotometrically (NanoDrop; Thermo Fisher).

cDNA template was synthesized from $1 \mu \mathrm{g}$ of total RNA with the use of NCode miRNA First-Strand cDNA Synthesis Kit (Thermo Fisher) according to the manufacturer's protocol. Quantitative PCR (qPCR) was performed with StepOne Plus Real-Time PCR (Applied Biosystems
Thermo Fisher) in a mixture that contained $1 \times$ concentrated SYBR Green PCR Master Mix (Sigma-Aldrich), $10 \mu \mathrm{mol} / \mathrm{L}$ primers forward and reverse (Tables 1 and 2) (universal reverse primer for miRNAs was supplied by the vendor), and $2 \mu \mathrm{L}$ of cDNA ( $10 \times$ diluted). Gene expression was normalized to a constitutive gene (EF2) or small RNA (U6). Relative quantification of gene expression was calculated according to the comparative $\Delta \mathrm{C}_{\mathrm{T}}$ (threshold cycle value) method.

\section{RT-qPCR on SCs}

RT-qPCR on SCs was performed with AmpliSpeed system (Beckman Coulter Biomedical, Pasadena, CA). Fifty SCs per field on AmpliGrid slides were sorted and dried overnight at $4^{\circ} \mathrm{C}$. RT reaction was performed with NCode VILO miRNA cDNA Synthesis directly on the slide on AmpliSpeed cycler. The obtained cDNA was used for qPCR reaction.

\section{Protein Isolation}

Total protein was isolated from snap-frozen muscle fragments by homogenization in $1 \mathrm{~mL}$ of lysis buffer (PBS $+1 \%$ Triton X-100) that contained inhibitors of proteinases (Roche Diagnostic, Basel, Switzerland), according to the vendor's protocol.

\section{Luminex Cytokine Assay}

Concentrations of IL-1 $\beta$, IL-6, MCP-1, monokine induced by interferon(IFN)- $\gamma$ (MIG), IL-12, IFN- $\gamma$-induced protein (IP)-10, and VEGF were measured in plasma or in the protein isolated from muscles with the use of Milliplex FlexMap 3D (Millipore, Billerica, MA) according to the vendor's protocol.

\section{Statistical Analysis}

Data are presented as means \pm SEM. Differences between groups were tested for statistical significance with the use of the unpaired 2-tailed $t$-test or $U$ test for comparison of two groups, and analysis of variance with Bonferroni posttest when changes in multiple time points were analyzed. Grubb's test was used to identify statistically significant outliers. $P<0.05$ was considered as significant.

\section{Results}

Lack of H0-1 Enhances Skeletal Muscle Degeneration and Inflammation after CTX-Induced Injury

In Hmoxl $I^{+/+}$animals the induction of Hmoxl expression appeared on the first (mRNA) and third (protein) day after myoinjury, followed by a steady state decrease on subsequent days, concomitantly to decreasing inflammation (Figure 1, A and B and Supplemental Figure S1). HO-1 was 
Table 1 Sequence of Primers Used in the Research

\begin{tabular}{lll}
\hline Transcript & Sequence of starters \\
\hline EF2 & Forward & $5^{\prime}$-GACATCACCAAGGGTGTGCAG-3' \\
& Reverse & $5^{\prime}$-TCAGCACACTGGCATAGAGGC-3' \\
H0-1 & Forward & $5^{\prime}$-CCTCACTGGCAGGAAATCATC-3' \\
& Reverse & $5^{\prime}$-CCTCGTGGAGACGCTTTACATA-3' \\
SDF-1 $\alpha$ & Forward & $5^{\prime}$-CCTTCAGATTGTTGCACGGCTGA-3' \\
& Reverse & $5^{\prime}$-CCCACCACTGCCCTTGCATG-3' \\
VEGF & Forward & $5^{\prime}$-ATGCGGATCAAACCTCACCAAGGC-3' \\
& Reverse & $5^{\prime}$-TTAACTCAAGCTGCCTCGCCTTGC-3' \\
Myf5 & Forward & $5^{\prime}$-CCTGTCTGGTCCCGAAAGAAC-3' \\
& Reverse & $5^{\prime}$-GACGTGATCCGATCCACAATG-3' \\
myoD & Forward & $5^{\prime}$-GCTGCCTTCTACGCACCTG-3' \\
& Reverse & $5^{\prime}$-GCCGCTGTAATCCATCATGC-3' \\
myogenin & Forward & $5^{\prime}$-CAGTACATTGAGCGCCTACAG-3' \\
& Reverse & $5^{\prime}$-GGACCGAACTCCAGTGCAT-3' \\
Pax7 & Forward & $5^{\prime}$-CAACCACATGAACCCTGTCA-3' \\
& Reverse & $5^{\prime}$-GAGATGGAGGAAGCCGAGTC-3' \\
IL-1 $\beta$ & Forward & $5^{\prime}$-CTGGTGTGTGACGTTCCCATTA-3' \\
& Reverse & $5^{\prime}$-CCGACAGCACGAGGCTTT-3' \\
IGF-1 & Forward & $5^{\prime}$-CTGGTGGATGCTCTTCAGTT-3' \\
& Reverse & $5^{\prime}$-GCTGCTTTTGTAGGCTTCAG-3' \\
\hline
\end{tabular}

H0, heme oxygenase; IGF, insulin-like growth factor; Pax7, paired box protein 7; SDF, stromal cell-derived factor; VEGF, vascular endothelial growth factor.

expressed in cells infiltrating muscle: $\mathrm{CD}^{+} 5^{+}$leukocytes, including $\mathrm{F} 4 / 80^{+}$macrophages (Figure 1C), and did not colocalize with apoptotic cells (TUNEL staining) (Supplemental Figure S1). In HO-1-deficient animals plasma activity of muscle degeneration markers (CPK, LDH) were elevated on the first day after CTX injection to a higher level than in $\mathrm{Hmoxl}^{+/+}$counterparts (Figure 2, A and B). The activity of LDH decreased from day 3 in both groups, but it remained higher in $\mathrm{Hmoxl}^{-/-}$mice. Moreover, histologic analysis (Figure 2, C and D) and staining of necrotic fibers (Figure 2E) presented more pronounced muscle degeneration and inflammatory infiltration on the third day after injury in $\mathrm{Hmoxl}^{-/-}$mice.

In skeletal muscle of $\mathrm{Hmoxl}^{-/-}$mice increased protein level of proinflammatory MCP-1, IL- 6 on the first and third day after injury was found (Figure 3A). Although IL-1 $\beta$ protein was below the threshold of detection, IL-1 $\beta$ was elevated at the mRNA level (Figure 3B). Similarly, in plasma of injured Hmoxl ${ }^{-/-}$animals MCP-1 and IL-1 $\beta$ were elevated, although no difference was found in the level of IL-6 (Figure 3C). It was accompanied by an increased

Table 2 Sequence of miRNA Primers Used in the Research

\begin{tabular}{ll}
\hline miRNA & Sequence of starters \\
\hline U6 & $5^{\prime}$-CGCAAGGATGACACGCAAATTC-3' \\
miR-1 & 5'-GCTGGAATGTAAAGAAGTATGTAT-3' \\
miR-206 & $5^{\prime}$-TGGAATGTAAGGAAGTGTGTGG-3' \\
miR-133a/b & $5^{\prime}$-TTGGTCCCCTTCAACCAGCTGT-3' \\
\hline
\end{tabular}

concentration of MIG (CXCL9), IP-10 (CXCL10), and IL12 (Figure 3C).

\section{Decreased M1 and M1/M2 Ratio in $\mathrm{Hmox}^{-/-}$Animals after CTX Injury}

Increased inflammation in CTX-injected $\mathrm{Hmoxl}^{-/-}$mice was also evident by increased number of leukocytes and higher percentage of monocytes and granulocytes at the expense of lymphocyte fraction in peripheral blood (Figure 4A). However, enhanced infiltration of injured gastrocnemius was not observed with $\mathrm{CD} 45^{+} \mathrm{CD} 11 \mathrm{~b}^{+} \mathrm{F} 4 /$ $80^{+}$macrophages either on the first or third day of regeneration (Figure 4, B and C). More detailed FACS analysis of macrophage populations in skeletal muscles (Figure 4, B-F, and Supplemental Figure S2) showed that M1-like macrophages $\left(\mathrm{CD} 45^{+} \mathrm{CD} 11 \mathrm{~b}^{+} \mathrm{F} 4 / 80^{+} \mathrm{MHCII}^{\text {high }} \mathrm{CD} 206^{\text {low }}\right)$ were decreased in $\mathrm{HmoxI}^{-/-}$animals (Figure 4E) in contrast to M2-like macrophages $\left(\mathrm{CD} 45^{+} \mathrm{CD} 11 \mathrm{~b}^{+} \mathrm{F} 4 / 80^{+} \mathrm{MHCII}^{\text {low }}\right.$ CD206 ${ }^{\text {high }}$ ) (Figure 4F). Accordingly, M1/M2 ratio calculated for each mouse was significantly reduced in HO1-deficient animals (Figure 4D).

\section{Lack of H0-1 Increases Fiber Size Distribution and Arteriogenesis after CTX-Induced Injury}

Slight up-regulation of Pax7 expression was observed in the skeletal muscle in $\mathrm{Hmoxl}^{-/-}$animals on day 28 (Figure 5A), whereas mRNA level of MyoD, myogenin (Figure 5A), and Myf5 (data not shown) was unaffected by Hmoxl genotype. Similarly, no differences were found in the level of miR-1 (Figure 5A). Accelerated induction of miR-133a/b and miR-206 was visible in skeletal muscles of $\mathrm{Hmoxl}^{+/+}$animals in comparison with $\mathrm{Hmoxl}^{-/-}$mice (Figure 5A).

Changes in the percentage of newly formed fibers were not observed between mice of different Hmoxl genotypes (Figure 5B) and mean cross-sectional area (Figures 5D and 2D). However, more detailed analysis of the size of regenerating myofibers on the 28th day after injury revealed that Hmoxl ${ }^{-1-}$ muscle fibers of bigger size tend to be more frequent than in animals with normal HO-1 level (Figure 5C). Moreover, Hmoxl ${ }^{-/-}$regenerating fibers on the 28th day achieved similar size distribution to the one observed in intact muscles (day 0), whereas in $\mathrm{HmoxI}^{+/+}$ animals this process was slower (Figure 5C). Accordingly, a tendency to increased level of IGF-1 was observed in skeletal muscles of $\mathrm{Hmoxl}^{-/-}$animals throughout the process of regeneration after myotrauma (Figure 5E).

Staining of collagen deposition (Supplemental Figure S3A) and FACS analysis of FAP cells $\left(\mathrm{CD} 45^{-} \mathrm{CD} 31^{-} \alpha 7 \mathrm{i}^{-} \mathrm{Sca} 1^{+} \mathrm{CD} 34^{+}\right.$) (Supplemental Figure S3B) did not show differences in the rate of fibrosis between $\mathrm{Hmoxl}^{+/+}$and Hmoxl ${ }^{-/-}$animals. However, increased rate of arteriogenesis occurred in $\mathrm{Hmoxl}^{-/-}$animals, as reflected by a higher number of positive $\alpha$-smooth muscle actin arterioles on the 28th day after injury (Supplemental Figure S4A). 
A

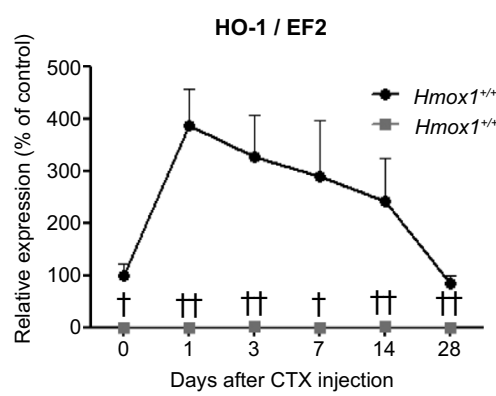

B

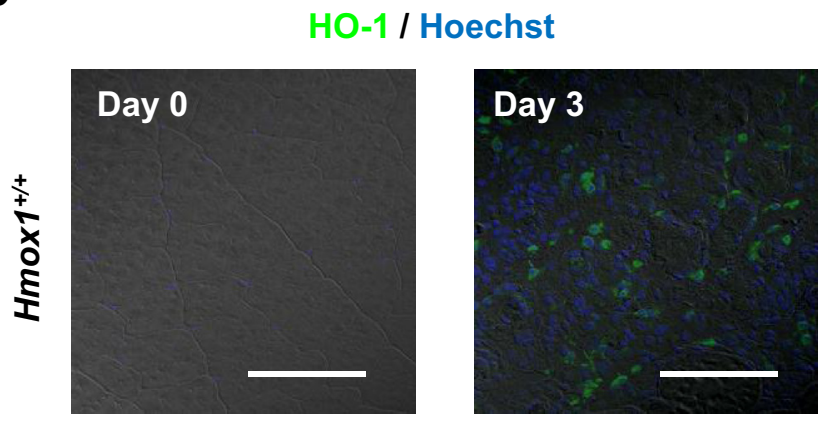

C

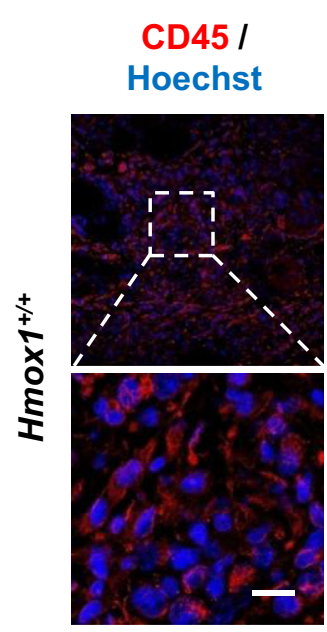

$\mathrm{HO}-1 /$ Hoechst

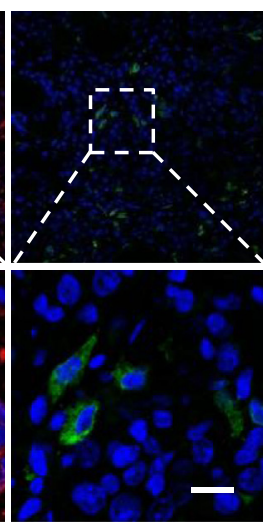

$\mathrm{HO}-1$ I

CD45 I Hoechst

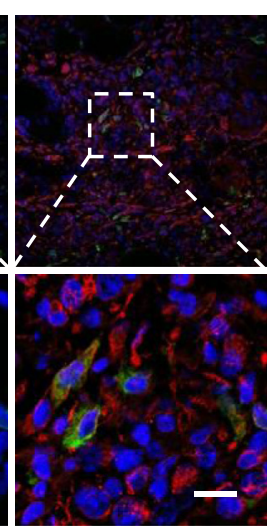

$\mathrm{F} 4 / 80$ / Hoechst

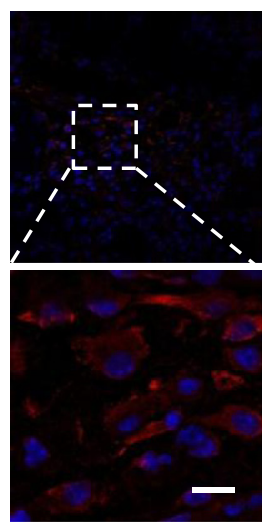

$\mathrm{HO}-1 /$

F $4 / 80$ I

HO-1 I Hoechst Hoechst
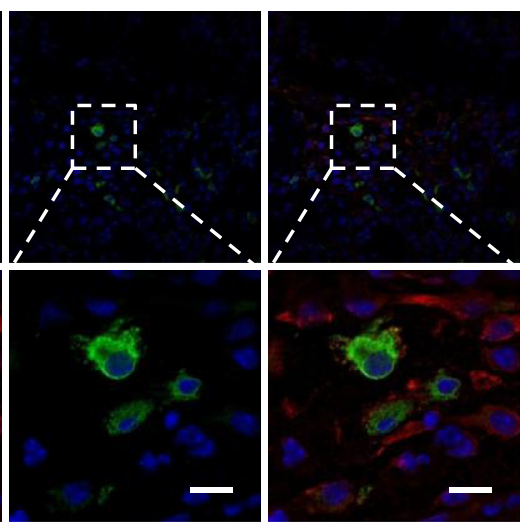

Figure 1 Heme oxygenase-1 (H0-1) expression in gastrocnemius muscle of $H \operatorname{mox} 1^{+/+}$and Hmox $1^{-/-}$animals after cardiotoxin (CTX)-induced injury in gastrocnemius muscle. A and B: H0-1 mRNA level; quantitative RT-PCR (A) and protein level; immunohistofluorescence staining (B); representative images. C: Cellular expression of $\mathrm{HO}-1$ in $\mathrm{CD}_{4} 5^{+}$and $\mathrm{F} 4 / 80^{+}$cells; immunohistofluorescence staining; representative images. Data are expressed as means $\pm \mathrm{SEM} . n=3$ to $5 .{ }^{\dagger} P<0.05,{ }^{\dagger \dagger} P<0.01$ versus $H \operatorname{mox} 1^{+/+}$. Scale bars: $10 \mu \mathrm{m}$ (B); $100 \mu \mathrm{m}$ (C).

Percentage of $\mathrm{CD}_{4} 5^{-} \mathrm{CD} 31^{+}$endothelial cells was similar in skeletal muscles regardless of the level of HO-1 (Supplemental Figure S4B), as well as the expression of mRNA of VEGF and stromal cell-derived factor- $1 \alpha$ in skeletal muscles (Supplemental Figure S4C). Hmoxl ${ }^{-/-}$animals had, however, a higher concentration of VEGF in their plasma 1 and 3 days after injury (Supplemental Figure S4D).

Lack of H0-1 Enhances Proliferation of SCs on the First Few Days after CTX Injury

To examine if SCs were affected in $\mathrm{Hmoxl}^{-/-}$mice, FACS analysis of SCs was performed (Figure 6A). $\mathrm{CD} 45^{-} \mathrm{CD} 31^{-} \mathrm{Sca}^{-} \alpha 7 \mathrm{i}^{+} \mathrm{CD} 34^{+}$SCs revealed no differences both in quantity and proliferation between mice of different Hmoxl genotypes (Figure 6B). However, activated SCs, lacking expression of CD34, $\left(\mathrm{CD} 45^{-} \mathrm{CD} 31^{-} \mathrm{Sca} 1^{-} \alpha 7 \mathrm{i}^{+} \mathrm{CD} 34^{-}\right)$were decreased in Hmoxl ${ }^{-/-}$mice on the third day after CTX injection (Figure 6C). At this time proliferation of
$\mathrm{CD} 45^{-} \mathrm{CD} 31^{-} \mathrm{Sca} 1^{-} \alpha 7 \mathrm{i}^{+} \mathrm{CD} 34^{-}$cells was increased in Hmoxl $^{-1-}$ mice (Figure 6C), which was also confirmed by higher number of $\mathrm{Pax} 7^{+} \mathrm{Edu}{ }^{+}$cells in muscle sections on the first day after injury (Figure 6D and Supplemental Figure S5A).

Analysis of the expression of $\mathrm{Pax} 7$ in $\mathrm{SCs}$ showed its raised level in $\mathrm{CD} 45^{-} \mathrm{CD} 31^{-} \mathrm{Sca} 1^{-} \alpha 7 \mathrm{i}^{+} \mathrm{CD} 34^{-}$Hmoxl ${ }^{-1-}$ cells in intact muscles (Figure 6E), but no differences were found 1 day after CTX injection (Figure 6F). No changes in miR-1 and miR-206 between SCs of different genotypes were visible (Supplemental Figure S5B).

\section{In Vitro Stimulation of $\mathrm{Hmox}^{+/+} \mathrm{SCs}$ with}

Proinflammatory Cytokines Partially Mimics the Effect of H0-1 Deficiency on Proliferation

We hypothesized that increased proliferation of SCs may be attributed to elevated concentration of proinflammatory cytokines in Hmoxl $^{-/-}$skeletal muscles (Figure 3, A and $\mathrm{B})$. Therefore $\mathrm{CD} 45^{-} \mathrm{CD} 31^{-} \mathrm{Sca} 1^{-} \alpha 7 \mathrm{i}^{+}$cells were 




D
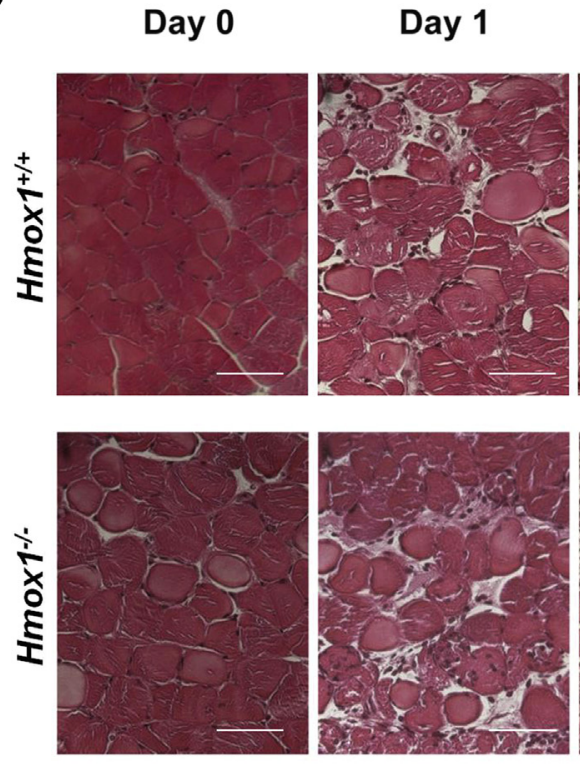

B

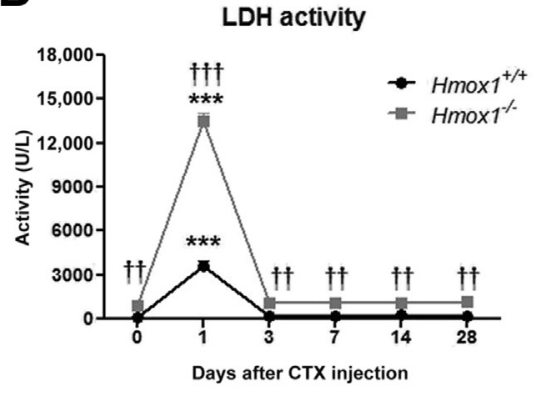

Day 3
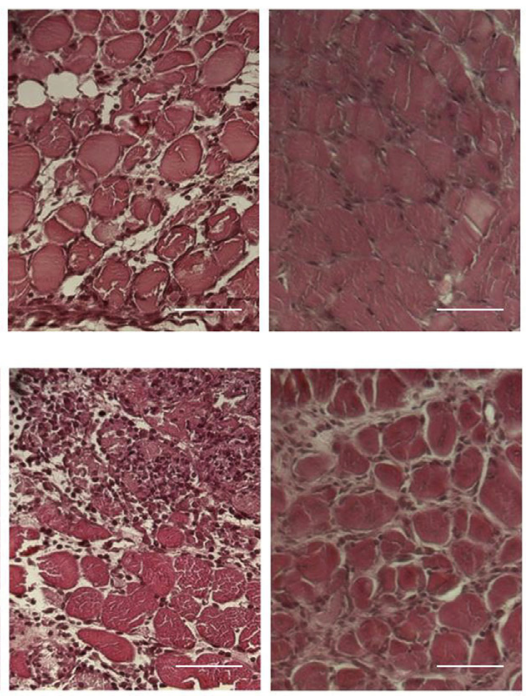

C

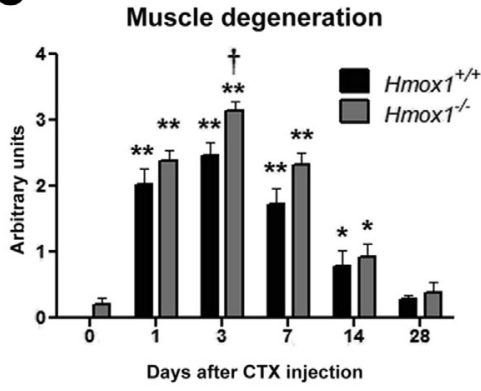

Day 14

Day 28


\section{E}



$\operatorname{Hmox} 1^{+/+}$

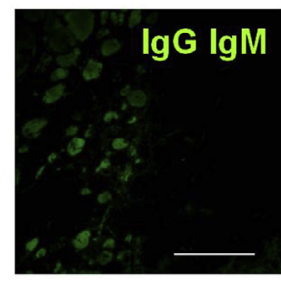

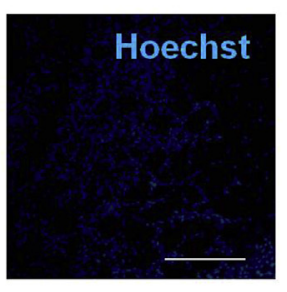

$H \operatorname{mox} 1^{\%}$
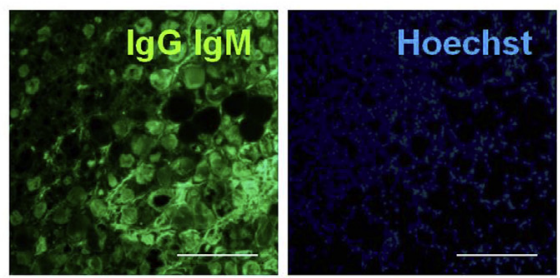

Figure 2 Cardiotoxin (CTX)-induced injury in gastrocnemius muscle of $H \mathrm{Hox}^{+/+}$and $\mathrm{Hmox} \mathrm{1}^{-/-}$animals. A and B: Creatine phosphokinase (CPK) (A) and lactate dehydrogenase (LDH) (B) activity in plasma; activity assay. C: Microscopic assessment of gastrocnemius muscle degeneration; semiquantitative assessment. D: Representative images of hematoxylin and eosin-stained gastrocnemius muscle. E: Microscopic assessment of myofiber necrosis 3 days after CTX, percentage of necrotic fiber among total fiber number in injured area and representative images. Data are expressed as means \pm SEM. $n=3$ to 5 . ${ }^{\star} P<0.05,{ }^{* *} P<0.01$, and ${ }^{* * *} P<0.001$ versus day $1 ;{ }^{\dagger} P<0.05,{ }^{\dagger \dagger} P<0.01$, and ${ }^{\dagger \dagger} P<0.001$ versus Hmox1 ${ }^{+/+}$. Scale bars: $100 \mu \mathrm{m}$ (D); $50 \mu \mathrm{m}$ (E).

isolated and stimulated with $100 \mathrm{ng} / \mathrm{mL} \mathrm{MCP}-1,1 \mathrm{ng} / \mathrm{mL}$ IL-6, and $0.1 \mathrm{ng} / \mathrm{mL}$ IL-1 $\beta$ for 24 hours. Slightly but statistically significant increased percentage of SCs was observed in the $\mathrm{S}$ phase on cytokine stimulation (Figure 7A). Importantly, HO-1-deficient SCs proliferated more intensively than wild-type counterparts. Simultaneously, increased percentage of $\mathrm{MyoD}^{+}$cells among Hmoxl ${ }^{-1-}$ SCs and SCs stimulated with cytokines was found (Figure 7B).
Subsequent Phases of Myotrauma and Tissue Regeneration throughout a Life Span Lead to Exhaustion of SCs in $\mathrm{Hmox}^{-/-}$Skeletal Muscle

To examine the effect of HO-1 level in multiple rounds of muscle injury and regeneration, mice of different Hmoxl genotypes were injected three times with CTX with 2-week intervals, and all analyses were performed after the third injury. Analysis of SCs on the third day after final injection of CTX 

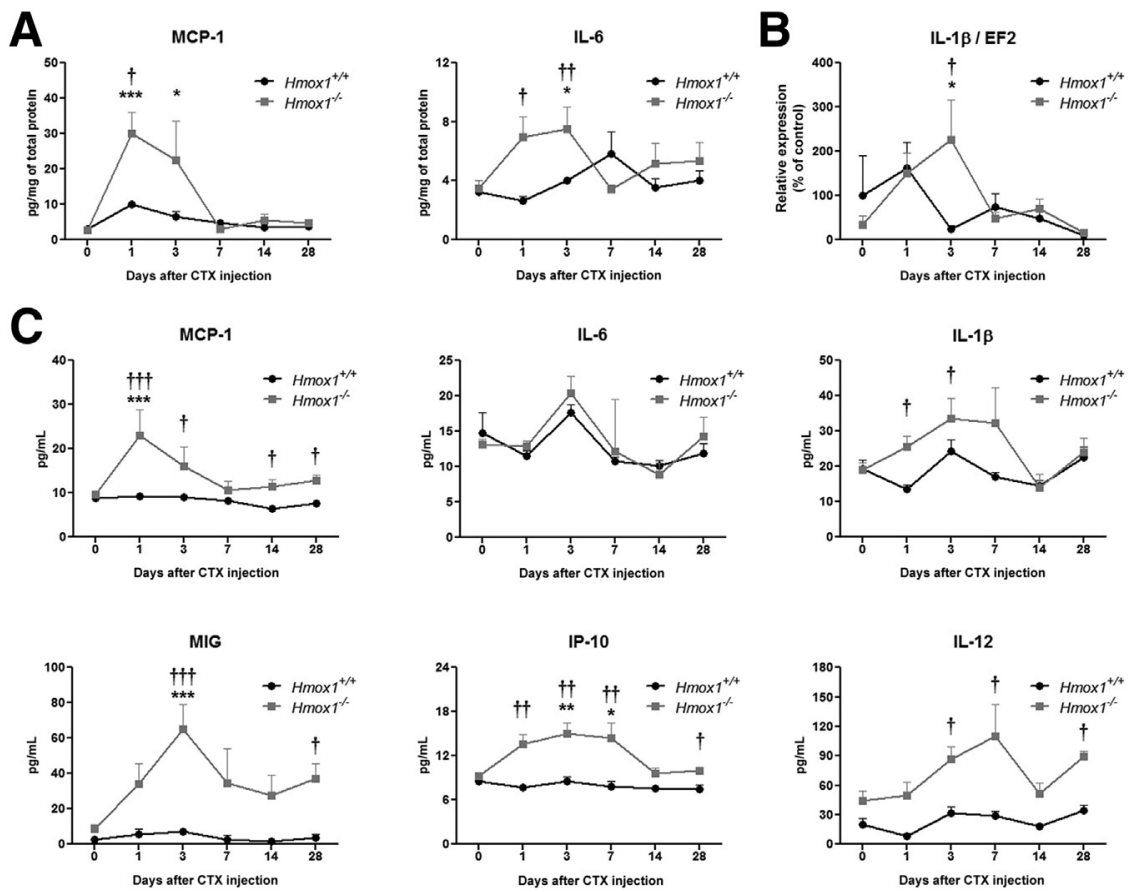

Figure 3 Level of proinflammatory cytokines in cardiotoxin (CTX)-injured gastrocnemius muscle and plasma of $\mathrm{Hmox}^{+/+}$and $\mathrm{Hmox}^{-/-}$animals. A: Monocyte chemoattractant protein (MCP)-1 and IL-6 protein level in gastrocnemius muscle; Milliplex. B: IL-1 $\beta$ mRNA level in gastrocnemius muscle, quantitative RT-PCR. C: Protein level of MCP-1, IL-6, IL-1 $\beta$, monokine induced by interferon (IFN)$\gamma$ (MIG; CXCL9), IFN- $\gamma$-induced protein (IP)-10 (CXCL10), IL-12 in plasma; Milliplex. Data are expressed as means \pm SEM. $n=3$ to $5 .{ }^{*} P<0.05$, $* * P<0.01$, and $* * * P<0.001$ versus day 1 ; ${ }^{\dagger} P<0.05,{ }^{\dagger \dagger} P<0.01$, and ${ }^{\dagger \dagger} P<0.001$ versus $\mathrm{Hmox}^{+/+}$. revealed decreased number of $\mathrm{CD} 45^{-} \mathrm{CD} 31^{-} \mathrm{Sca} 1^{-}$ $\alpha 7 \mathrm{i}^{+} \mathrm{CD} 34^{-}$with no changes in $\mathrm{CD} 45^{-} \mathrm{CD} 31^{-} \mathrm{Sca} 1^{-} \alpha 7 \mathrm{i}^{+}$ $\mathrm{CD}_{3}{ }^{+} \mathrm{SC}$ quantity (Figure $8, \mathrm{~A}$ and $\mathrm{B}$ ). Proliferation rate

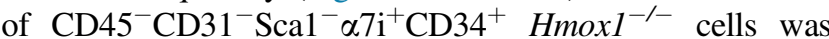
decreased on the first day on the third injury (Figure 8, A and B). Similarly to animals subjected to single injection of CTX, higher level of leukocytes, with increased proportion of granulocytes and monocytes, and decreased lymphocyte percentage were observed in Hmox $1^{-/-}$animals (Supplemental Figure S6A). Increased CPK and LDH activity was visible in plasma of $\mathrm{HmoxI}^{-1-}$ mice (Supplemental Figure S6B), with no changes in the level of muscle degeneration and regeneration (Supplemental Figure S6C). In addition, on the first day of the final injury M1-like macrophages $\left(\mathrm{CD} 45^{+} \mathrm{CD} 11 \mathrm{~b}^{+} \mathrm{F} 4 /\right.$ $80^{+} \mathrm{MHCII}^{\text {high }} \mathrm{CD} 206^{\text {low }}$ ) were decreased in $\mathrm{Hmoxl}^{-/-}$mice. Similar tendency was observed on the third day both in M1 and


phages, resulting in a decrease of total macrophage quantity at this time point (Supplemental Figure S6D).

Finally, SC quantity was analyzed in $H_{m o x} l^{+/+}$and $H$ mox $I^{-1-}$ mice of different age, demonstrating decreased number of both quiescent and activated SCs in 24-month-old animals lacking HO-1 (Figure 8C).

\section{Discussion}

Skeletal muscles are characterized by a high oxygen consumption; thus, enzymes with antioxidant properties were shown to be protective in this tissue. ${ }^{30}$ High level of oxidative metabolism and reactive oxygen species generation in skeletal muscle is associated with expression of HO- $1,{ }^{31,32}$ that is additionally increased after a series of contractions $^{31,32}$ and is correlated to myoglobin content. ${ }^{33}$ It was suggested that HO-1 can therefore protect against exercise-induced injury, ${ }^{32,34}$ whereas its lack increases apoptosis in skeletal muscles on ischemia. ${ }^{27}$ Accordingly, in skeletal muscles of Hmox $1^{+/+}$mice in response to CTX an induction of HO-1 expression was observed, which did not colocalize with the presence of apoptotic cells. Accordingly, HO-1 expression was found elevated, particularly in cells infiltrating the muscle-CD45 ${ }^{+}$leukocytes, including F4/ $80^{+}$macrophages. Similar localization of $\mathrm{HO}-1$ is also visible after chronic injury in the murine model of Duchenne muscular dystrophy ( $m d x$ mice). ${ }^{35}$ Therefore, HO-1 may be considered as a factor responsible for restricting the intensity of muscle injury. Indeed, a potent elevation of plasma markers of muscle degeneration (CPK, $\mathrm{LDH}$ ), accompanied by enhanced injury in skeletal muscle tissue, was observed in $H \operatorname{mox} 1^{-1-}$ animals.

Of note, myogenic cells can be a source of MCP-1, IL-6, and $\mathrm{IL}-1 \beta{ }^{36-38}$ which was found elevated in $H \operatorname{mox} 1^{-/-}$ skeletal muscle. Those cytokines were down-regulated by HO-1 in other cell types. ${ }^{39,40}$ Persistent HO-1 expression prevents up-regulation of MCP-1 in response to heme and contributes to tissue protection. ${ }^{41}$ Therefore, induction of IL-6, IL-1 $\beta$, and MCP-1 in the injured HO-1-deficient skeletal muscles may be considered as a disturbance of this protective mechanism.

Enhanced inflammatory reaction that is characteristic for mice lacking $\mathrm{HO}-1^{16,17}$ was also reflected in the increased number of circulating leukocytes in CTXinjured $\mathrm{Hmoxl}^{-/-}$animals. Interestingly, in response to local injury, percentage of granulocytes and monocytes in peripheral blood of Hmox $1^{-/-}$mice was elevated at the expense of lymphocytes. Monocytes are considered as 
A

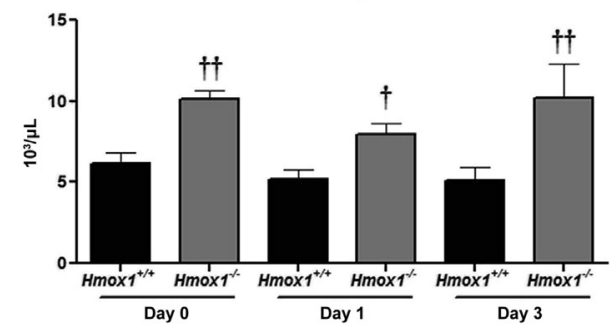

Granulocytes

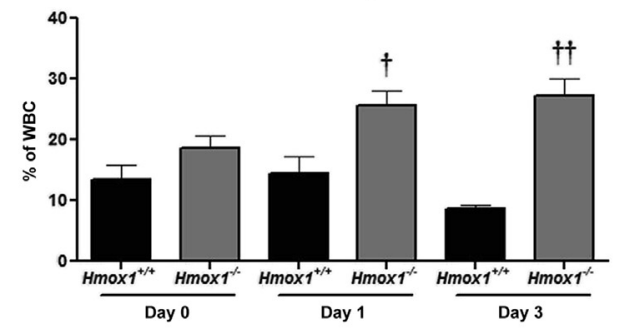

Monocytes

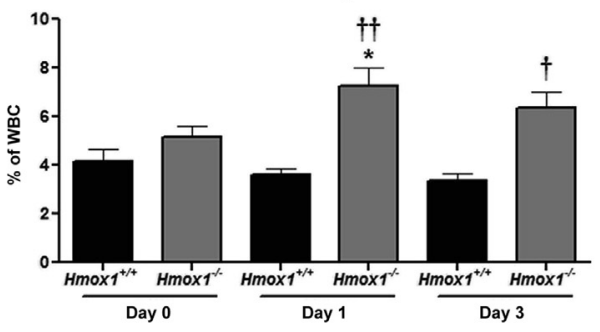

Lymphocytes

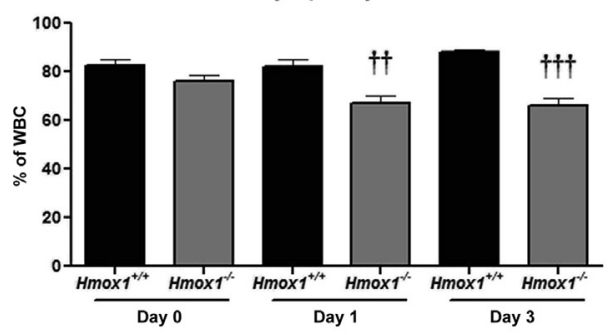

B
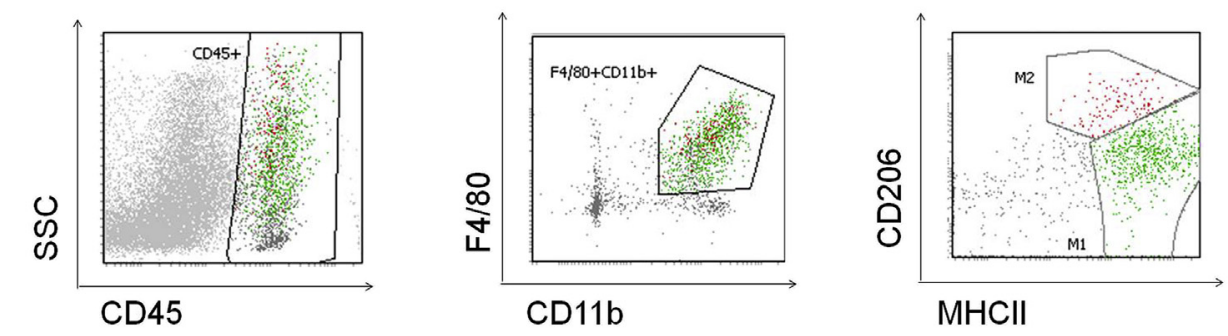

C

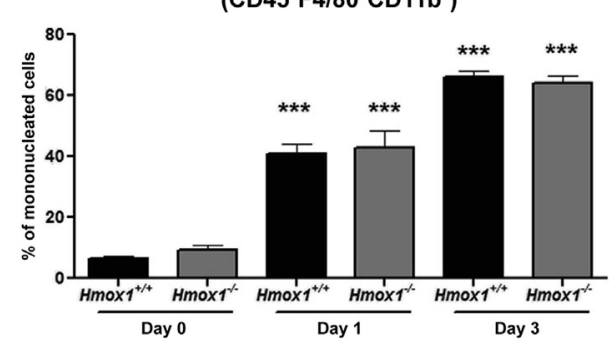

E

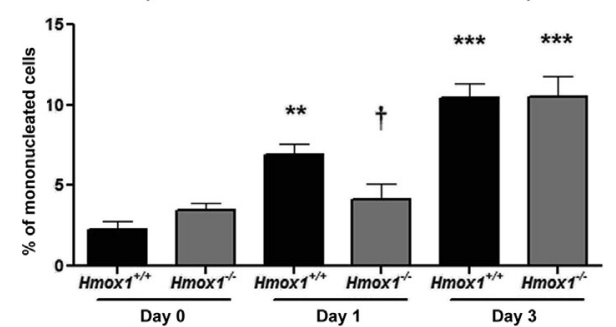

D

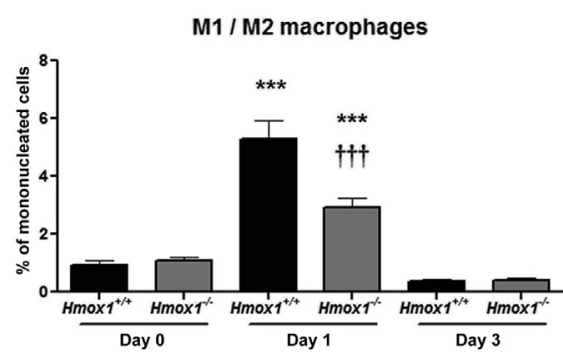

$\mathbf{F}$

M2-like macrophages (CD45+F4/80+CD11b+MHCII $\left.{ }^{10} \mathrm{CD} 20^{\text {hi }}\right)$

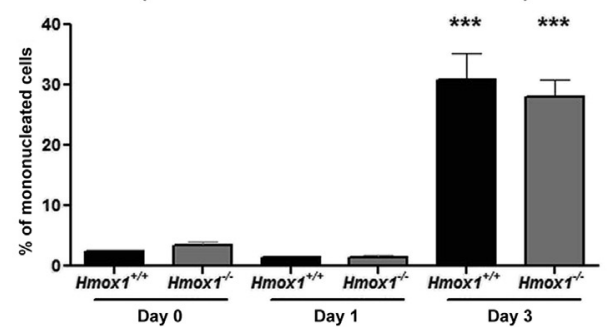

Figure 4 Level of leukocytes in the peripheral blood and macrophages in gastrocnemius muscle of cardiotoxin (CTX)-injected $H$ mox $1^{+/+}$and $H$ mox $1^{-/-}$ animals. A: Total blood cell count from peripheral blood. B: Gating strategy of $\mathrm{CD} 45^{+} \mathrm{F} 4 / 80^{+} \mathrm{CD} 11 \mathrm{~b}^{+}$cells (macrophages), $\mathrm{CD} 45^{+} \mathrm{F} 4 / 80^{+} \mathrm{CD} 11 \mathrm{~b}^{+}$major his-

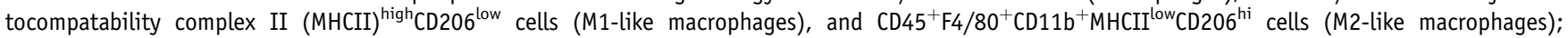
fluorescence-activated cell sorting (FACS). C-F: Macrophages (C), M1/M2 macrophages ratio (D), M1-like macrophages (E), M2-like macrophages (F) in gastrocnemius muscle; FACS. Data are expressed as means \pm SEM. $n=5 .{ }^{*} P<0.05,{ }^{*} P<0.01$, and ${ }^{* * *} P<0.001$ versus day 1 ; ${ }^{\dagger} P<0.05,{ }^{\dagger \dagger} P<0.01$, and ${ }^{\dagger \dagger \dagger} P<0.001$ versus $\mathrm{Hmox}^{+/+}$. SSC, side scatter. 
A

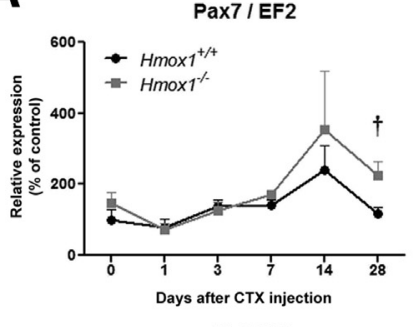

miR-1 / 66

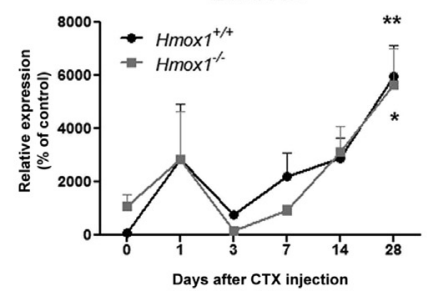

B

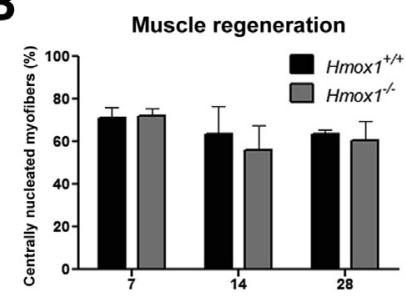

Days after CTX injection

D Mean fiber cross-sectional area
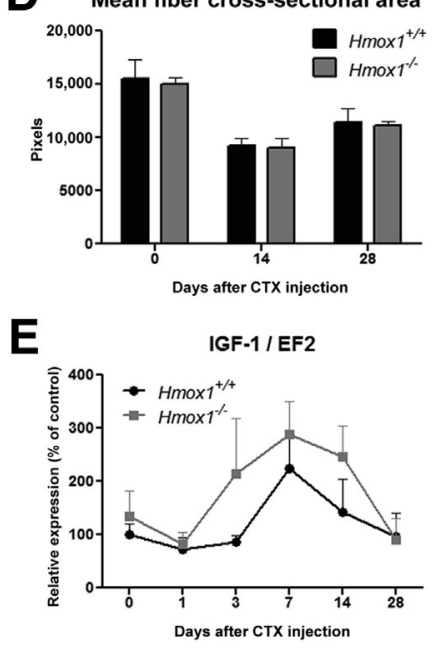


$\mathrm{miR}-133 \mathrm{a} / \mathrm{b} / \mathrm{U} 6$
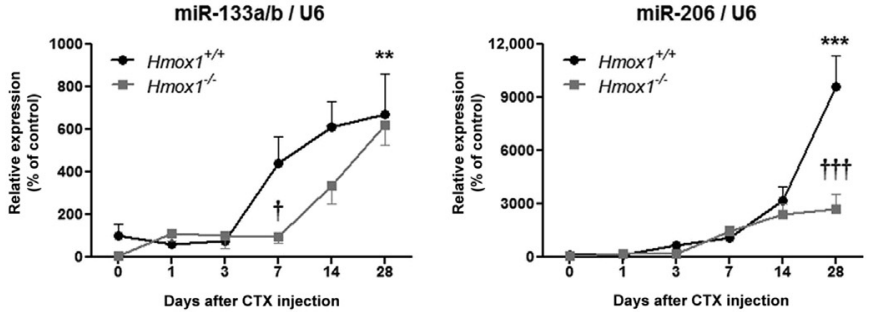

C Myofiber size in intact muscles


Figure 5 Skeletal muscle regeneration in cardiotoxin (CTX)-injured gastrocnemius muscle of $H \operatorname{mox} 1^{+/+}$and $H$ mox $1^{-/-}$animals. A: Paired box protein 7 (Pax7), MyoD, myogenin, miR-1, miR-133a/b, and miR-206 on mRNA level; quantitative RT-PCR (RT-qPCR). B: Percentage of centrally nucleated fibers; semiquantitative assessment. C: Percentage of myofibers of different size in intact muscle (day 0) and regenerating myofibers (days 14 and 28 ). D: Mean crosssection area of the fibers. E: Insulin-like growth factor (IGF)-1 on mRNA level; RT-qPCR. Data are expressed as means \pm SEM. $n=4$ to 5 . ${ }^{*} P<0.05$, $* * P<0.01$, and $* * * P<0.001$ versus day $1 ;{ }^{\dagger} P<0.05,{ }^{\dagger \dagger} P<0.001$ versus $H$ mox $1^{+/+}$.

major sources of MCP-1, IL-1 $\beta$, and IL-12. ${ }^{42-44}$ Accordingly, increased concentration of those proinflammatory cytokines was also observed in the plasma of Hmox $1^{-/-}$animals in response to CTX. Although changes in the level of IFN- $\gamma$ were not observed between groups (data not shown), IFN- $\gamma$-related cytokines MIG
(CXCL9) and IP-10 (CXCL10) were elevated in the plasma of Hmoxl ${ }^{-1-}$ animals.

Despite increased monocyte percentage in peripheral blood and potent induction of MCP-1 in skeletal muscles, augmented infiltration of $\mathrm{CD} 45^{+} \mathrm{CD} 11 \mathrm{~b}^{+} \mathrm{F} 4 / 80^{+}$macrophages was not observed after injury in $\mathrm{Hmoxl}^{-1-}$ skeletal 


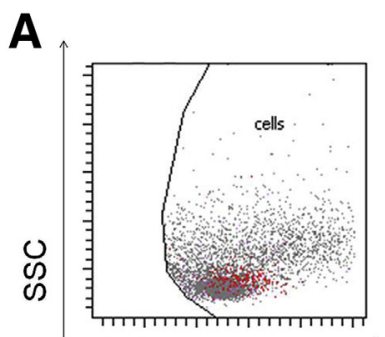

FCS



CD31

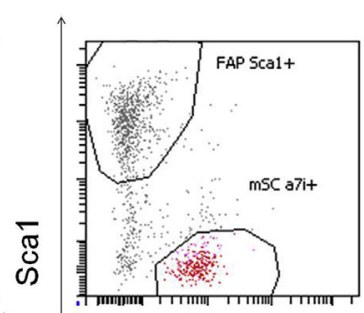

$\alpha 7$ integrin

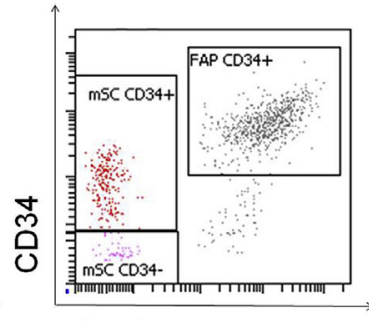

Sca1

B

SC (CD45-CD31-Sca1- $\alpha 7^{-} i^{+}$CD34+)


C
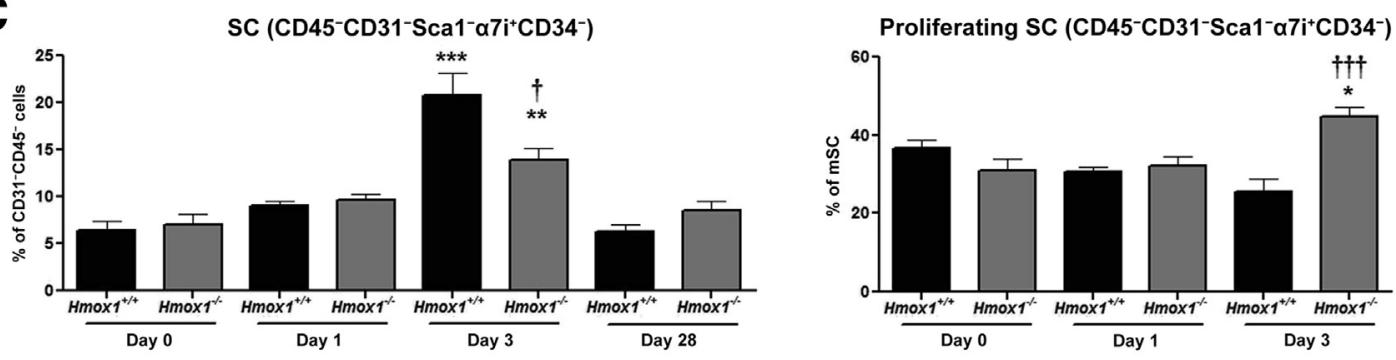

D
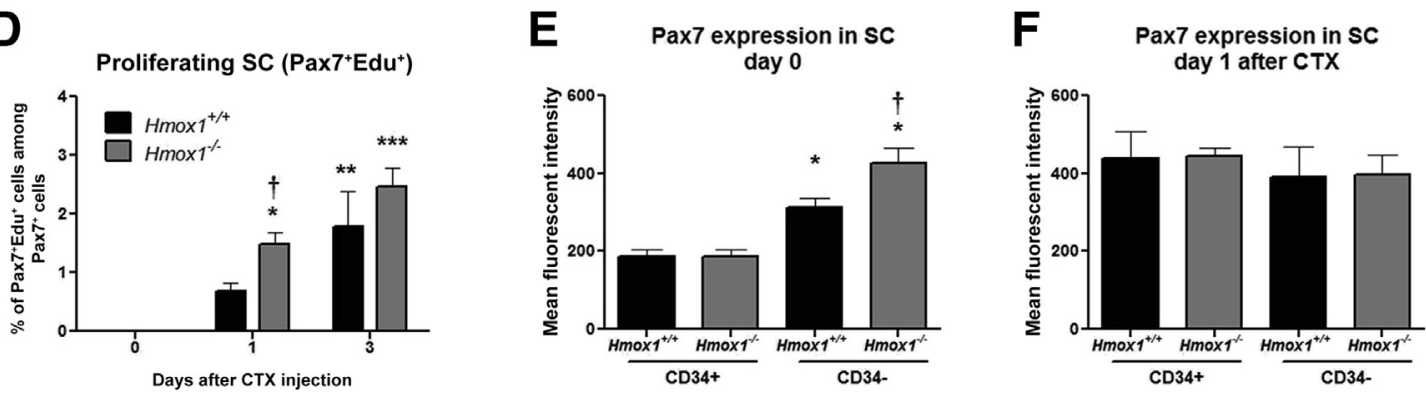

Figure 6 Satellite cell (SC) quantity and proliferation in cardiotoxin (CTX)-injured gastrocnemius muscle of $H$ mox $1^{+/+}$and $H$ mox $1^{-/-}$animals. A: Gating strategy of $\mathrm{CD} 45^{-} \mathrm{CD} 31^{-}$stem cell antigen-1 (Sca1) ${ }^{-} \alpha 7 \mathrm{i}^{+} \mathrm{CD} 34^{+}$cells (SCs) and $\mathrm{CD} 45^{-} \mathrm{CD} 31^{-} \mathrm{Sca} 1^{-} \alpha 7 \mathrm{i}^{+} \mathrm{CD} 34^{-}$cells (activated SCs); fluorescence-activated cell sorting (FACS). B: Percentage of SCS and proliferating SCS; FACS. C: Percentage of activated SCS and proliferating activated SCS; FACS. D: Percentage of proliferating SCs [paired box protein $7(\operatorname{Pax} 7)^{+} / 5$-ethynyl-2-deoxyuridine $\left(\mathrm{Edu}^{+}\right)$] among Pax $7^{+}$cells; immunohistofluorescence staining of paraffin section. E and F: Level of Pax7 protein in SCS (E) and activated SCS (F); FACS. Data are expressed as means \pm SEM. $n=4$ to $10 .{ }^{*} P<0.05$, ${ }^{* *} P<0.01$, and ${ }^{* * *} P<0.001$ versus day $1 ;{ }^{\dagger} P<0.05,{ }^{\dagger \dagger \dagger} P<0.001$ versus Hmox $1^{+/+}$. FCS, forward scatter; SSC, side scatter.

muscle. On the contrary, when percentage of proinflammatory macrophages (M1-like phenotype, $\mathrm{MHCII}^{+} \mathrm{C}-$ D206 ${ }^{\text {low }},{ }^{5}$ ) was analyzed, there was a tendency to their delayed accumulation. Accordingly, a ratio of M1-like/M2like macrophages was changed on the first day after injury in $H_{m o x l^{-/}}$animals. Decreased proportion of M1/M2 macrophages observed in HO-1-deficient mice may influence angiogenesis ${ }^{21}$ and fibrosis ${ }^{46}$ within skeletal muscle. However, differences were not observed either in FAP cells or collagen deposition between Hmoxl ${ }^{+/+}$and Hmoxl $I^{-1-}$ mice. Declined ratio of M1/M2 macrophages, as well as increased concentration of plasma VEGF and MCP-1, can induce blood vessel formation ${ }^{21,47}$ and, hence, may increase arteriole formation in $\mathrm{HmoxI}^{-/-}$mice.

Because macrophages are indispensable mediators of myogenic regeneration, ${ }^{8}$ it may be suspected that decreased ratio of M1-like population affects restoration of muscle architecture. However, expression of muscle regulatory factors (MyoD, Myf5, myogenin) was not changed in HO-1-deficient mice during skeletal muscle regeneration. 
A
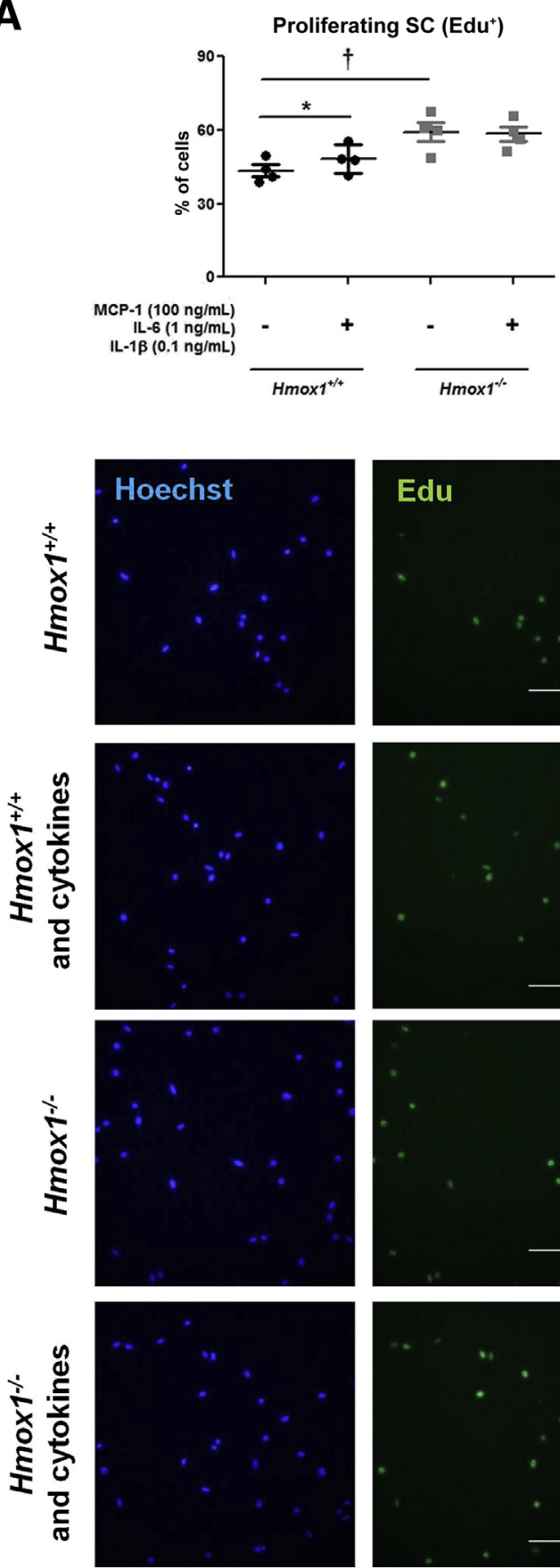


B


Figure 7 In vitro proliferation and level of MyoD in satellite cell (SC) culture stimulated with monocyte chemoattractant protein (MCP)-1, IL-6, IL-1ß. A: Percentage of 5-ethynyl-2-deoxyuridine (Edu) ${ }^{+}$cells in SC culture; immunocytochemical staining. B: Percentage of Myo $D^{+}$cells in SC culture; immunocytochemical staining. Each dot represents cells from 1 animal. $n=4 .{ }^{\star} P<0.05$ versus unstimulated control; ${ }^{\dagger} P<0.05$ versus $H$ mox $1^{+/+}$. Scale bars $=100 \mu \mathrm{m}$.

No differences were observed in the expression of miR-1; however, miR-206 and miR-133a/b were down-regulated in Hmoxl ${ }^{-/}$animals. Reduction in miR-206 level in Hmoxl ${ }^{-/-}$skeletal muscle on the 28th day after CTX injection corresponded with an increased expression of Pax7, which is a target of miR-206 also on the mRNA level. ${ }^{48}$ Although the lack of HO-1 was shown to induce miR-206 expression in primary myoblasts cultured in vitro, ${ }^{25,26}$ during regeneration of injured muscle this effect is apparently overwhelmed by the impact of proinflammatory cytokines, which inhibit myomirs expression ${ }^{49}$ and are elevated in muscles of $\mathrm{HmoxI}^{-1-}$ mice.

Although no variation in the percentage of newly formed myofibers was found in CTX-injected mice of different Hmoxl genotype, or mean cross-sectional area, regenerating myofibers of larger size tended to be more frequent in Hmoxl ${ }^{-/-}$mice than in Hmoxl $I^{+/+}$animals. Furthermore, they achieved distribution of size presented by intact muscle 
A

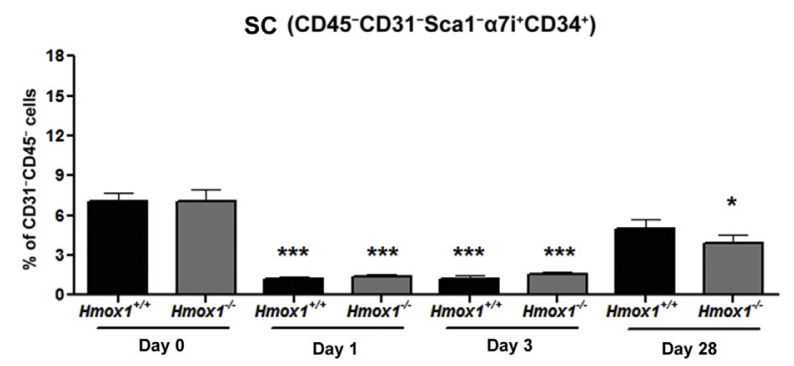

B

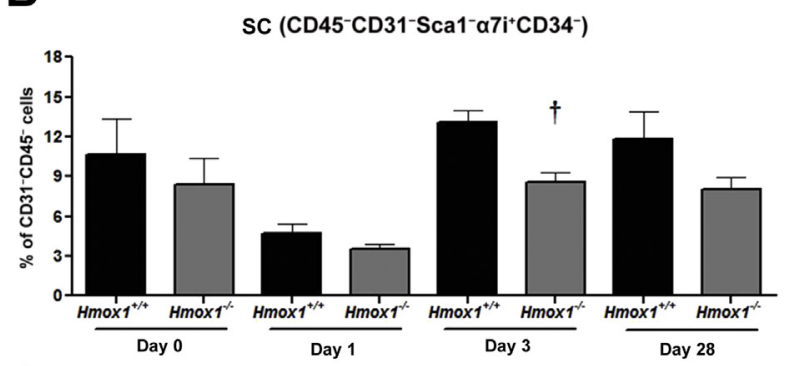

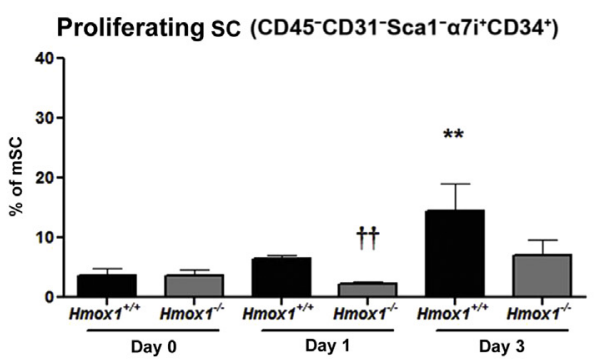

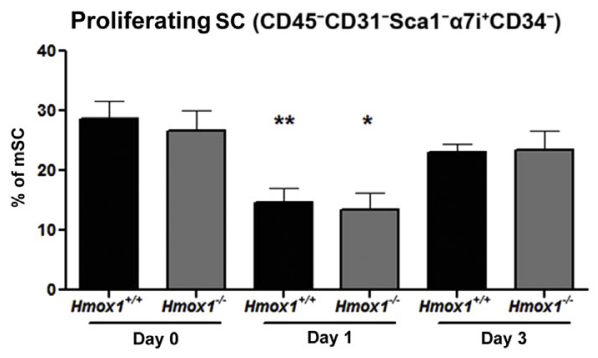

C SC (CD45-CD31-Sca1- $\left.\alpha 7^{-C D}{ }^{+}{ }^{+} 4^{+}\right)$


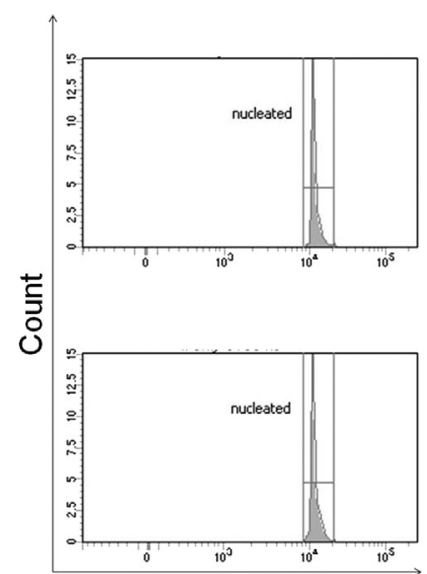

Hoechst

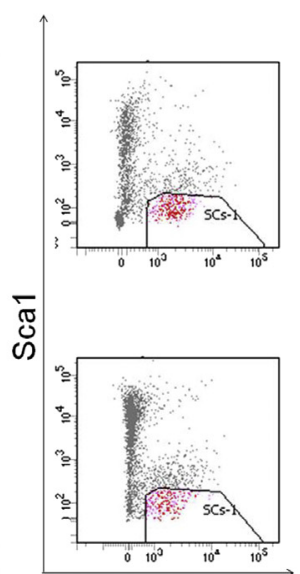

$\alpha 7$ integrin

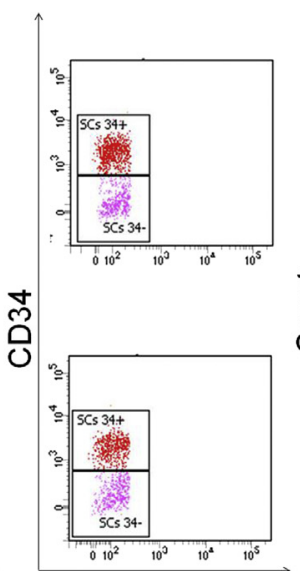

Sca1

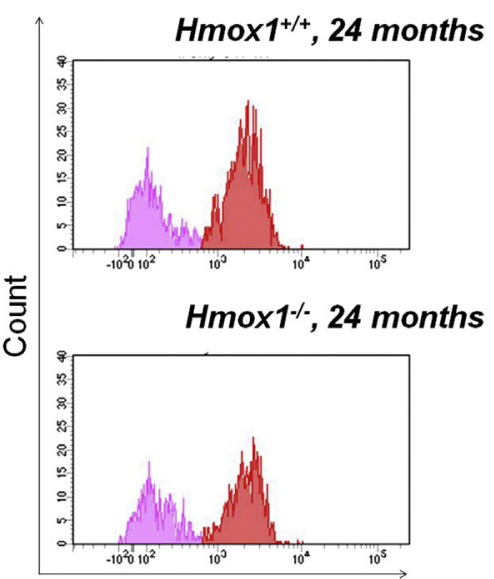

CD34

Figure 8 Changes in satellite cell (SC) quantity and proliferation in gastrocnemius muscle of $H \operatorname{mox} 1^{+/+}$and $H$ mox $1^{-/-}$animals after repeated rounds of injury-regeneration and with age. A and B: Percentage and proliferation of quiescent (A) and activated (B) SCs in gastrocnemius muscle of $H m o \times 1^{+/+}$and Hmox $1^{-/-}$control animals after triple injection of cardiotoxin (CTX); fluorescence-activated cell sorting (FACS). C: Percentage of SCs and activated SCs in different ages of $\mathrm{Hmox}^{+/+}$and $\mathrm{Hmox} 1^{-/-}$animals and representative images from FACS analysis of SCs of $H \operatorname{mox} 1^{+/+}$and $H \operatorname{mox} 1^{-/-} 24-m o n t h-o l d$ animals for the same number of nucleated cells. Data are expressed as means \pm SEM. $n=4$ to 9 . ${ }^{*} P<0.05, * * P<0.01$, and ${ }^{* * *} P<0.001$ versus day $1 ;{ }^{\dagger} P<0.05$, ${ }^{\dagger \dagger} P<0.01$ versus $H \operatorname{mox} 1^{+/+}$. Sca1, stem cell antigen-1.

earlier then muscles of normal HO-1 level. This moderate effect on myofiber maturation might first be partially ascribed to increased IGF-1 expression, which is a known factor that affects the diameter of muscle fibers. ${ }^{2,5}$ Second, a potent induction of proinflammatory cytokines observed in Hmoxl $1^{-/}$muscles can also result in hypertrophy, because MCP- $1^{50}$ and IL- $6^{51,52}$ were shown to induce myofiber size. Third, miR-206 is expressed in regenerating myofibers, ${ }^{53}$ 
acting there as a factor to reduce hypertrophy. ${ }^{54}$ Because its lower expression is found in $H_{m o x l}{ }^{-1-}$ animals, it may be an additional factor to increase fiber diameter. Higher expression of miR-206 in Hmoxl ${ }^{+/+}$mice may be also a sign that myofibers are immature and are still regenerating. Finally, M2 macrophages were shown to promote fusion and differentiation of $\mathrm{SCs}^{8}$; thus, elevated proportion of $\mathrm{M} 2$ population in $\mathrm{Hmoxl}^{-/-}$animals may be responsible for the enlarged myofiber.

SCs in skeletal muscles of Hmoxl ${ }^{+/+}$and Hmoxl ${ }^{-1-}$ mice were analyzed because they might affect the regeneration rate of skeletal muscle. Increased proliferation of both $\operatorname{Pax} 7^{+}$cells on the first day of regeneration and activated SCs $\left(\mathrm{CD} 45^{-} \mathrm{CD} 31^{-} \mathrm{Sca1}{ }^{-} \alpha 7 \mathrm{i}^{+} \mathrm{CD} 34^{-}\right)^{55-57}$ isolated from skeletal muscle of $\mathrm{Hmoxl}^{-/-}$animals on the third day after injury was observed. Despite this, no differences were observed in the quantity of SCs $\left(\mathrm{CD} 45^{-} \mathrm{CD} 31^{-} \mathrm{Sca} 1^{-} \alpha 7 \mathrm{i}^{+} \mathrm{CD} 34^{+}\right)$; however, the number of activated SCs $\left(\mathrm{CD} 45^{-} \mathrm{CD} 31^{-} \mathrm{Sca} 1^{-} \alpha 7 \mathrm{i}^{+} \mathrm{CD} 34^{-}\right)$was even decreased in $H$ mox $I^{-1-}$ mice. This effect does not appear to be mediated by the miR-1 or miR-206 because no differences were observed in their expression in SCs. However, activated SCs from HO-1-deficient mice showed higher expression of Pax7. It was shown, that Pax7 is necessary for cell cycle entry because it induces expression of genes that promote proliferation of SCs and therefore allows their population to expand. ${ }^{58-60}$ Hence, elevated expression of Pax7 may make Hmoxl ${ }^{-1-}$ SCs predisposed to accelerated activation.

Proinflammatory cytokines (MCP-1, IL-1 $\beta$, IL-6) are known to induce proliferation of SCs. ${ }^{51,52,61,62}$ In vitro stimulation of $\mathrm{HmoxI}^{+/+} \mathrm{SCs}$ with these cytokines enhanced proliferation, although not to the level observed in SCs lacking HO-1. In addition, SCs stimulated with proinflammatory cytokines and SCs of $\mathrm{Hmoxl}^{-/-}$phenotype presented increased expression of MyoD, which is in accordance to previously observed effects of HO-1 deficiency in primary myoblasts. ${ }^{25}$ Therefore, we suggest that both the lack of HO-1 in SCs and the stimulation of SCs with MCP-1, IL-1 $\beta$, IL-6 cocktail accelerated their proliferation and shifted SCs toward more differentiated myogenic population. This is in accordance with the accelerated proliferation of $\mathrm{Hmoxl}^{-1-}$ SCs after CTX injury, hypertrophic effect observed in mice of $\mathrm{Hmoxl}^{-/-}$ genotype, and with the previous results that showed the increased differentiation potential of cells with decreased level of HO- $1 .^{24}$

It was further examined whether differences between Hmoxl $I^{+/+}$and Hmoxl ${ }^{-/-}$muscles can be augmented after repeated injury. In $H_{m o x} I^{-1-}$ animals subjected to triple CTX injection similar global changes as in animals with single injury were observed: increased leukocytes in peripheral blood with increased proportion of granulocytes and monocytes, increased LDH and CPK plasma activity, decreased M1-like and total macrophage infiltration into skeletal muscle, without significant differences in muscle damage or regeneration. However, in contrast to single injury, subsequent rounds of muscle damage followed by myogenic restoration seem to depress proliferation of Hmoxl ${ }^{-1-}$ SCs, what may be a reason for lower number of activated SCs observed on a third day after final CTX injection. The quantity of SC population remains usually stable despite multiple injures within skeletal muscle. ${ }^{63}$ Thus, it can be speculated that the proper level of HO-1 during muscle injury may ensure protection against precocious activation of SCs observed in Hmoxl ${ }^{-/-}$mice, where repeated rounds of degeneration/regeneration can impair proliferation of SCs and in turn decrease their number.

During a lifetime a reduction in the number of SCs was observed. ${ }^{64-66}$ Therefore, the quantity of SCs in sedentary skeletal muscles of $\mathrm{Hmoxl}^{+/+}$and $\mathrm{Hmoxl}^{-/-}$mice was analyzed. In 24-month-old Hmoxl $I^{-/-}$animals a reduced pool of SCs was found. SCs-depleted mice cannot regenerate muscle at all after CTX injury, ${ }^{67-69}$ and decreased number of SCs is one of the factors to impair the regenerative capacity in aged skeletal muscle ${ }^{70,71}$ although it does not affect steady state conditions of the tissue. ${ }^{64,70}$ Of note, in Duchenne muscular dystrophy, in which continuous rounds of muscular degeneration and regeneration may lead to exhaustion of the SC pool, hampered regeneration was also shown. ${ }^{72}$ It might be speculated that impaired HO-1 expression may additionally potentiate this effect.

\section{Conclusions}

It was shown that the lack of HO-1 augments skeletal muscle injury and expression of proinflammatory MCP-1, IL-6, and IL-1 $\beta$ during the regeneration process in animals subjected to CTX injection. Disturbed proportion of M1/M2 macrophages with a tendency to diminished M1 population, together with increased IL-6, MCP-1, and IGF-1, accompanied by enhanced formation of arterioles may be responsible for hypertrophic effect and increased rate of regeneration observed in injured $\mathrm{Hmoxl}^{-1-}$ skeletal muscle. Finally, HO1-deficient SCs are prone to activation and have higher proliferation after injury. This effect can be partially mimicked by stimulation of Hmoxl ${ }^{+/+}$SCs with MCP-1, IL-6, and IL-1 $\beta$ and is associated with increased MyoD expression, suggesting that SCs from $\mathrm{Hmoxl}^{-/-}$animals are shifted toward more differentiated myogenic population.

\section{Acknowledgments}

We thank administrative staff Agnieszka Andrychowicz-Rog and Joanna Uchto-Bajolek for their assistance and Ewa Werner, Anna Gese, and Ryszard Czypicki (Jagiellonian University, Krakow, Poland) for technical help with experiments on animals. C57BL/6xFVB Hmoxl ${ }^{+/+}$and Hmoxl $I^{-1-}$ breeding pairs were originally provided by Dr. Anupam Agarwal (University of Alabama, Birmingham, AL). 
M.K. and J.D. designed the experiments; M.K., K.B.-S., A.L., A.J., and J.D. analyzed the data; M.K., K.P.-G., M.C., M.S., I.B.-B., P.P., and K.B.-S. performed research; and M.K., A.J., and J.D. wrote the paper.

\section{Supplemental Data}

Supplemental material for this article can be found at https://doi.org/10.1016/j.ajpath.2017.10.017.

\section{References}

1. Sciorati C, Rigamonti E, Manfredi AA, Rovere-Querini P: Cell death, clearance and immunity in the skeletal muscle. Cell Death Differ 2016, 23:927-937

2. Karalaki M, Fili S, Philippou A, Koutsilieris M: Muscle regeneration: cellular and molecular events. In Vivo 2009, 23:779-796

3. Tidball JG: Mechanisms of muscle injury, repair, and regeneration. Compr Physiol 2011, 1:2029-2062

4. Yin H, Price F, Rudnicki MA: Satellite cells and the muscle stem cell niche. Physiol Rev 2013, 93:23-67

5. Brzoska E, Ciemerych MA, Przewozniak M, Zimowska M: Regulation of muscle stem cells activation: the role of growth factors and extracellular matrix. Vitam Horm 2011, 87:239-276

6. Bentzinger CF, Wang YX, Dumont NA, Rudnicki MA: Cellular dynamics in the muscle satellite cell niche. EMBO Rep 2013, 14: 1062-1072

7. Pillon NJ, Bilan PJ, Fink LN, Klip A: Cross-talk between skeletal muscle and immune cells: muscle-derived mediators and metabolic implications. Am J Physiol Endocrinol Metab 2013, 304: E453-E465

8. Saclier M, Cuvellier S, Magnan M, Mounier R, Chazaud B: Monocyte/Macrophage interactions with myogenic precursor cells during skeletal muscle regeneration. FEBS J 2013, 280:4118-4130

9. Kharraz Y, Guerra J, Mann CJ, Serrano AL, Munoz-Canoves P: Macrophage plasticity and the role of inflammation in skeletal muscle repair. Mediat Inflamm 2013, 2013:491497

10. Dumont NA, Wang YX, Rudnicki MA: Intrinsic and extrinsic mechanisms regulating satellite cell function. Development 2015, 142:1572-1581

11. Almada AE, Wagers AJ: Molecular circuitry of stem cell fate in skeletal muscle regeneration, ageing and disease. Nat Rev Mol Cell Biol 2016, 17:267-279

12. Olguin HC, Pisconti A: Marking the tempo for myogenesis: Pax7 and the regulation of muscle stem cell fate decisions. J Cell Mol Med 2012, 16:1013-1025

13. Relaix F, Zammit PS: Satellite cells are essential for skeletal muscle regeneration: the cell on the edge returns centre stage. Development 2012, 139:2845-2856

14. Novak ML, Koh TJ: Phenotypic transitions of macrophages orchestrate tissue repair. Am J Pathol 2013, 183:1352-1363

15. Chazaud B, Brigitte M, Yacoub-Youssef H, Arnold L, Gherardi R, Sonnet C, Lafuste P, Chretien F: Dual and beneficial roles of macrophages during skeletal muscle regeneration. Exerc Sport Sci Rev 2009, 37:18-22

16. Loboda A, Jazwa A, Grochot-Przeczek A, Rutkowski AJ, Cisowski J, Agarwal A, Jozkowicz A, Dulak J: Heme oxygenase-1 and the vascular bed: from molecular mechanisms to therapeutic opportunities. Antioxid Redox Signal 2008, 10:1767-1812

17. Grochot-Przeczek A, Dulak J, Jozkowicz A: Haem oxygenase-1: noncanonical roles in physiology and pathology. Clin Sci (Lond) 2012, 122:93-103
18. Ryter SW, Choi AM: Targeting heme oxygenase-1 and carbon monoxide for therapeutic modulation of inflammation. Transl Res 2016, 167:7-34

19. Naito Y, Takagi T, Higashimura Y: Heme oxygenase-1 and antiinflammatory M2 macrophages. Arch Biochem Biophys 2014, 564: $83-88$

20. Gozzelino R, Jeney V, Soares MP: Mechanisms of cell protection by heme oxygenase-1. Annu Rev Pharmacol Toxicol 2010, 50:323-354

21. Szade A, Grochot-Przeczek A, Florczyk U, Jozkowicz A, Dulak J: Cellular and molecular mechanisms of inflammation-induced angiogenesis. IUBMB Life 2015, 67:145-159

22. Zarjou A, Agarwal A: Heme oxygenase-1 as a target for TGF-beta in kidney disease. Semin Nephrol 2012, 32:277-286

23. Loboda A, Stachurska A, Podkalicka P, Sobczak M, Mucha O, Witalisz-Siepracka A, Jozkowicz A, Dulak J: Effect of heme oxygenase-1 on ochratoxin A-induced nephrotoxicity in mice. Int J Biochem Cell Biol 2017, 84:46-57

24. Kozakowska M, Szade K, Dulak J, Jozkowicz A: Role of heme oxygenase- 1 in postnatal differentiation of stem cells: a possible cross-talk with micrornas. Antioxid Redox Signal 2014, 20: $1827-1850$

25. Kozakowska M, Ciesla M, Stefanska A, Skrzypek K, Was H, Jazwa A, Grochot-Przeczek A, Kotlinowski J, Szymula A, Bartelik A, Mazan M, Yagensky O, Florczyk U, Lemke K, Zebzda A, Dyduch G, Nowak W, Szade K, Stepniewski J, Majka M, Derlacz R, Loboda A, Dulak J, Jozkowicz A: Heme oxygenase-1 inhibits myoblast differentiation by targeting myomirs. Antioxid Redox Signal 2012, 16:113-127

26. Ciesla M, Marona P, Kozakowska M, Jez M, Seczynska M, Loboda A, Bukowska-Strakova K, Szade A, Walawender M, Kusior M, Stepniewski J, Szade K, Krist B, Yagensky O, Urbanik A, Kazanowska B, Dulak J, Jozkowicz A: Heme oxygenase-1 controls an HDAC4-miR-206 pathway of oxidative stress in rhabdomyosarcoma. Cancer Res 2016, 76:5707-5718

27. Jazwa A, Stepniewski J, Zamykal M, Jagodzinska J, Meloni M, Emanueli C, Jozkowicz A, Dulak J: Pre-emptive hypoxia-regulated HO-1 gene therapy improves post-ischaemic limb perfusion and tissue regeneration in mice. Cardiovasc Res 2013, 97:115-124

28. Straub V, Rafael JA, Chamberlain JS, Campbell KP: Animal models for muscular dystrophy show different patterns of sarcolemmal disruption. J Cell Biol 1997, 139:375-385

29. Liu N, Williams AH, Maxeiner JM, Bezprozvannaya S, Shelton JM, Richardson JA, Bassel-Duby R, Olson EN: Microrna206 promotes skeletal muscle regeneration and delays progression of Duchenne muscular dystrophy in mice. J Clin Invest 2012, 122: 2054-2065

30. Kozakowska M, Pietraszek-Gremplewicz K, Jozkowicz A, Dulak J: The role of oxidative stress in skeletal muscle injury and regeneration: focus on antioxidant enzymes. J Muscle Res Cell Motil 2015, 36: 377-393

31. Essig DA, Borger DR, Jackson DA: Induction of heme oxygenase-1 (HSP32) mRNA in skeletal muscle following contractions. Am J Physiol 1997, 272:C59-C67

32. Pilegaard H, Ordway GA, Saltin B, Neufer PD: Transcriptional regulation of gene expression in human skeletal muscle during recovery from exercise. Am J Physiol Endocrinol Metab 2000, 279: E806-E814

33. Vesely MJ, Sanders R, Green CJ, Motterlini R: Fibre type specificity of haem oxygenase-1 induction in rat skeletal muscle. FEBS Lett 1999, 458:257-260

34. Saxena S, Shukla D, Saxena S, Khan YA, Singh M, Bansal A, Sairam M, Jain SK: Hypoxia preconditioning by cobalt chloride enhances endurance performance and protects skeletal muscles from exercise-induced oxidative damage in rats. Acta Physiol (Oxf) 2010, 200:249-263

35. Hnia K, Hugon G, Rivier F, Masmoudi A, Mercier J, Mornet D: Modulation of p38 mitogen-activated protein kinase cascade and metalloproteinase activity in diaphragm muscle in response to free 
radical scavenger administration in dystrophin-deficient Mdx mice. Am J Pathol 2007, 170:633-643

36. Lu H, Huang D, Ransohoff RM, Zhou L: Acute skeletal muscle injury: CCL2 expression by both monocytes and injured muscle is required for repair. FASEB J 2011, 25:3344-3355

37. Munoz-Canoves P, Scheele C, Pedersen BK, Serrano AL: Interleukin-6 myokine signaling in skeletal muscle: a double-edged sword? FEBS J 2013, 280:4131-4148

38. Peake JM, Della Gatta P, Suzuki K, Nieman DC: Cytokine expression and secretion by skeletal muscle cells: regulatory mechanisms and exercise effects. Exerc Immunol Rev 2015, 21:8-25

39. Orozco LD, Kapturczak MH, Barajas B, Wang X, Weinstein MM, Wong J, Deshane J, Bolisetty S, Shaposhnik Z, Shih DM, Agarwal A, Lusis AJ, Araujo JA: Heme oxygenase-1 expression in macrophages plays a beneficial role in atherosclerosis. Circ Res 2007, 100: $1703-1711$

40. Ke B, Shen XD, Gao F, Ji H, Qiao B, Zhai Y, Farmer DG, Busuttil RW, Kupiec-Weglinski JW: Adoptive transfer of ex vivo HO-1 modified bone marrow-derived macrophages prevents liver ischemia and reperfusion injury. Mol Ther 2010, 18:1019-1025

41. Pittock ST, Norby SM, Grande JP, Croatt AJ, Bren GD, Badley AD, Caplice NM, Griffin MD, Nath KA: Mcp-1 is up-regulated in unstressed and stressed HO-1 knockout mice: pathophysiologic correlates. Kidney Int 2005, 68:611-622

42. Deshmane SL, Kremlev S, Amini S, Sawaya BE: Monocyte chemoattractant protein-1 (MCP-1): an overview. J Interferon Cytokine Res 2009, 29:313-326

43. Snodgrass RG, Huang S, Choi IW, Rutledge JC, Hwang DH: Inflammasome-mediated secretion of IL-1beta in human monocytes through TLR2 activation; modulation by dietary fatty acids. J Immunol 2013, 191:4337-4347

44. Braun MC, Kelsall BL: Regulation of interleukin-12 production by G-protein-coupled receptors. Microbes Infect 2001, 3:99-107

45. Bosurgi L, Manfredi AA, Rovere-Querini P: Macrophages in injured skeletal muscle: a perpetuum mobile causing and limiting fibrosis, prompting or restricting resolution and regeneration. Front Immunol $2011,2: 62$

46. Mann CJ, Perdiguero E, Kharraz Y, Aguilar S, Pessina P, Serrano AL, Munoz-Canoves P: Aberrant repair and fibrosis development in skeletal muscle. Skelet Muscle 2011, 1:21

47. Shireman PK: The chemokine system in arteriogenesis and hind limb ischemia. J Vasc Surg 2007, 45 Suppl A:A48-A56

48. Chen JF, Tao Y, Li J, Deng Z, Yan Z, Xiao X, Wang DZ: microRNA1 and microRNA-206 regulate skeletal muscle satellite cell proliferation and differentiation by repressing Pax7. J Cell Biol 2010, 190: 867-879

49. Georgantas RW, Streicher K, Greenberg SA, Greenlees LM, Zhu W, Brohawn PZ, Higgs BW, Czapiga M, Morehouse CA, Amato A, Richman L, Jallal B, Yao Y, Ranade K: Inhibition of myogenic microRNAs 1, 133, and 206 by inflammatory cytokines links inflammation and muscle degeneration in adult inflammatory myopathies. Arthritis Rheumatol 2014, 66:1022-1033

50. Shireman PK, Contreras-Shannon V, Ochoa O, Karia BP, Michalek JE, McManus LM: MCP-1 deficiency causes altered inflammation with impaired skeletal muscle regeneration. J Leukoc Biol 2007, 81:775-785

51. Zhang C, Li Y, Wu Y, Wang L, Wang X, Du J: Interleukin-6/signal transducer and activator of transcription 3 (STAT3) pathway is essential for macrophage infiltration and myoblast proliferation during muscle regeneration. J Biol Chem 2013, 288:1489-1499

52. Serrano AL, Baeza-Raja B, Perdiguero E, Jardi M, MunozCanoves P: Interleukin-6 is an essential regulator of satellite cellmediated skeletal muscle hypertrophy. Cell Metab 2008, 7:33-44

53. Yuasa K, Hagiwara Y, Ando M, Nakamura A, Takeda S, Hijikata T: MicroRNA-206 is highly expressed in newly formed muscle fibers: implications regarding potential for muscle regeneration and maturation in muscular dystrophy. Cell Struct Funct 2008, 33:163-169
54. Winbanks CE, Beyer C, Hagg A, Qian H, Sepulveda PV, Gregorevic P: miR-206 represses hypertrophy of myogenic cells but not muscle fibers via inhibition of HDAC4. PLoS One 2013, 8: e73589

55. Beauchamp JR, Heslop L, Yu DS, Tajbakhsh S, Kelly RG, Wernig A, Buckingham ME, Partridge TA, Zammit PS: Expression of CD34 and Myf5 defines the majority of quiescent adult skeletal muscle satellite cells. J Cell Biol 2000, 151:1221-1234

56. Ieronimakis N, Balasundaram G, Rainey S, Srirangam K, YablonkaReuveni Z, Reyes M: Absence of CD34 on murine skeletal muscle satellite cells marks a reversible state of activation during acute injury. PLoS One 2010, 5:e10920

57. Alfaro LA, Dick SA, Siegel AL, Anonuevo AS, McNagny KM, Megeney LA, Cornelison DD, Rossi FM: CD34 promotes satellite cell motility and entry into proliferation to facilitate efficient skeletal muscle regeneration. Stem Cells 2011, 29:2030-2041

58. Soleimani VD, Punch VG, Kawabe Y, Jones AE, Palidwor GA, Porter CJ, Cross JW, Carvajal JJ, Kockx CE, van IJcken WF, Perkins TJ, Rigby PW, Grosveld F, Rudnicki MA: Transcriptional dominance of $\operatorname{Pax} 7$ in adult myogenesis is due to high-affinity recognition of homeodomain motifs. Dev Cell 2012, 22: $1208-1220$

59. von Maltzahn J, Jones AE, Parks RJ, Rudnicki MA: Pax7 is critical for the normal function of satellite cells in adult skeletal muscle. Proc Natl Acad Sci U S A 2013, 110:16474-16479

60. Gunther S, Kim J, Kostin S, Lepper C, Fan CM, Braun T: Myf5positive satellite cells contribute to Pax7-dependent long-term maintenance of adult muscle stem cells. Cell Stem Cell 2013, 13:590-601

61. Yahiaoui L, Grozdic D, Danialou G, Mack M, Petrof BJ: CC family chemokines directly regulate myoblast responses to skeletal muscle injury. J Physiol 2008, 586:3991-4004

62. Otis JS, Niccoli S, Hawdon N, Sarvas JL, Frye MA, Chicco AJ, Lees SJ: Pro-inflammatory mediation of myoblast proliferation. PLoS One 2014, 9:e92363

63. Shi X, Garry DJ: Muscle stem cells in development, regeneration, and disease. Genes Dev 2006, 20:1692-1708

64. Keefe AC, Lawson JA, Flygare SD, Fox ZD, Colasanto MP, Mathew SJ, Yandell M, Kardon G: Muscle stem cells contribute to myofibres in sedentary adult mice. Nat Commun 2015, 6:7087

65. Kadi F, Charifi N, Denis C, Lexell J: Satellite cells and myonuclei in young and elderly women and men. Muscle Nerve 2004, 29: $120-127$

66. Day K, Shefer G, Shearer A, Yablonka-Reuveni Z: The depletion of skeletal muscle satellite cells with age is concomitant with reduced capacity of single progenitors to produce reserve progeny. Dev Biol 2010, 340:330-343

67. Murphy MM, Lawson JA, Mathew SJ, Hutcheson DA, Kardon G: Satellite cells, connective tissue fibroblasts and their interactions are crucial for muscle regeneration. Development 2011, 138:3625-3637

68. Lepper C, Partridge TA, Fan CM: An absolute requirement for Pax7positive satellite cells in acute injury-induced skeletal muscle regeneration. Development 2011, 138:3639-3646

69. Sambasivan R, Yao R, Kissenpfennig A, Van Wittenberghe L, Paldi A, Gayraud-Morel B, Guenou H, Malissen B, Tajbakhsh S, Galy A: Pax7-expressing satellite cells are indispensable for adult skeletal muscle regeneration. Development 2011, 138:3647-3656

70. Fry CS, Lee JD, Mula J, Kirby TJ, Jackson JR, Liu F, Yang L, Mendias CL, Dupont-Versteegden EE, McCarthy JJ, Peterson CA: Inducible depletion of satellite cells in adult, sedentary mice impairs muscle regenerative capacity without affecting sarcopenia. Nat Med 2015, 21:76-80

71. Blau HM, Cosgrove BD, Ho AT: The central role of muscle stem cells in regenerative failure with aging. Nat Med 2015, 21:854-862

72. Jiang C, Wen Y, Kuroda K, Hannon K, Rudnicki MA, Kuang S: Notch signaling deficiency underlies age-dependent depletion of satellite cells in muscular dystrophy. Dis Model Mech 2014, 7: 997-1004 